\title{
Notes on Pterostichus subgenus Steropanus Fairmaire, 1889 (Coleoptera: Carabidae: Pterostichini), with descriptions of new species
}

\section{Заметки о подроде Steropanus Fairmaire, 1889 рода Pterostichus (Coleoptera: Carabidae: Pterostichini) с описанием новых видов}

\author{
D.N. Fedorenko \\ A.H. Федоренко
}

\begin{abstract}
A.N. Severtsov Institute of ecology and evolution, Leninsky pr. 33, Moscow 119071, Russia.
Институт проблем экологии и эволюции им. А.Н. Северцова, Российская Академия Наук, Ленинский пр-т 33, Москва 119071, Россия. E-mail: dmitri-fedorenko@yandex.ru
\end{abstract}

KEY WORDS: Coleoptera, Carabidae, Pterostichus, Steropanus, new species, Vietnam, Oriental region. КЛЮЧЕВЫЕ СЛОВА: Coleoptera, Carabidae, Pterostichus, Steropanus, новый вид, Вьетнам, Ориентальная область.

ABSTRACT. The subgenus Steropanus Fairmaire, 1889 of the genus Pterostichus Bonelli, 1810 is redescribed and a key to the species is provided. Six species are described: $P$. obliteratus, $P$. alveolatus, $P$. foveifrons, $P$. sulcatipennis, $P$. pseudoviolaceus, and $P$. asulcatus spp.n., all from Vietnam, and $P$. kataevi sp.n. from southern China.

РЕЗЮМЕ. Переописан подрод Steropanus Fairmaire, 1889 рода Pterostichus Bonelli, 1810. Coставлена таблица для определения видов подрода. Описаны 6 новых видов: $P$. obliteratus, $P$. alveolatus, P. foveifrons, $P$. sulcatipennis, $P$. pseudoviolaceus, and $P$. asulcatus spp.n., из Вьетнама и $P$. kataevi sp.n. с юга Китая.

\section{Introduction}

Pterostichini of Indochina, including Vietnam, are poorly studied. In the present paper, we describe six new species of Pterostichus subgenus Steropanus Fairmaire, 1889 and briefly review the subgenus.

Historically, Andrewes [1937] erected the genus Tritrichis for five species described by him from northern Vietnam, eastern India and Myanmar; the genus was considered as closely allied to Pterostichus Bonelli, 1810. Straneo [1949], Jedlička [1931, 1962] and Morvan [1992] contributed four more species to Tritrichis. Later, Sciaky [1996] synonymized Tritrichis with the monobasic genus Steropanus Fairmaire, 1889 from Yunnan, southern China, and downgraded it to a subge- nus of Pterostichus, based chiefly on the similarity between Steropanus and Pterostichus in male genitalia, as well as between Steropanus and the davidi-group of Pterostichus (currently the subgenus Orientostichus Sciaky et Allegro, 2013) in shape of the labial palps. He also synonymized $P$. (S.) infissus (Andrewes, 1937) with $P$. sulcibasis Straneo, 1989, which synonymy invited $P$. thailandicus (Straneo, 1989) to be the next member of Steropanus, since the species was described very near $P$. sulcibasis.

In treating Steropanus we follow Sciaky [1996] and Lorenz [1998], even though Bousquet [2003, 2017] and Lorenz [2005] restored its genus status.

Material was collected during several expeditions to montane regions in Vietnam, sponsored by the Joint Russia-Vietnam Tropical Center, Moscow-Hanoi.

Acronyms used are as follows: MSNM - Museo Civico di Storia Naturale, Milan; SIEE - the author's reference collection at A.N. Severtsov Institute of Ecology and Evolution, Russian Academy of Sciences, Moscow; ZISP - Zoological Institute, Russian Academy of Sciences, St. Petersburg; ZMMU — Zoological Museum of the Moscow State University.

The following parameters were analyzed:

$\mathrm{BL}$ - maximum body length measured between apices of closed mandibles and apex of elytra;

EL - maximum length of elytron, measured between apex and highest point of base;

EW - maximum width of elytra;

HW - width of head across eyes;

$\mathrm{PL}$ - length of pronotum along median line;

How to cite this article: Fedorenko D.N. 2018. Notes on Pterostichus subgenus Steropanus Fairmaire, 1889 (Coleoptera: Carabidae: Pterostichini), with descriptions of new species // Russian Entomol. J. Vol.27. No.2. P.107-121. doi: 10.15298/rusentj.27.2.01 
PLw - distance between apex and level of maximum width of pronotum, measured along mid-line; PW - maximum width of pronotum; $\mathrm{PWa}$ - width of pronotum between apical angles; $\mathrm{PWb}$ - width of pronotum between basal angles.

Measurements were taken using an eyepiece micrometer, to two decimal places. The number of specimens measured (n) is only given for the first ratio in the description. All labels are printed, unless marked ' $[\mathrm{hw}]$ ' (= handwritten). Data on labels of type specimens are in quotes.

\section{Results}

\section{Subgenus Steropanus Fairmaire, 1889}

Fairmaire, 1889: 10; Tschitschérine, 1897: 278; Sciaky, 1996: 430; Lorenz, 1998: 265; 2005: 287; Bousquet, 2003: 517; 2017 : 749. - Tritrichis Andrewes, 1937: 489 (type species: Tritrichis deliciata Andrewes, 1937); Jedlička, 1962: 306. typy).

Type species: Steropanus forticornis Fairmaire, 1889 (by mono-

REDESCRIPTION. Body (Figs 1-9) apterous, mediumsized, often slightly pedunculate, shiny or slightly dull, black to metallic violaceous. Legs mostly dark coloured, with tibiae reddish apicad or entirely. Antennae dark brown to reddishbrown, with segments 5-11 usually red at dorsal and ventral ridges. Labial palps brown to red; palpomeres, especially terminal ones, pale apically. Dorsal microsculpture meshed, very superficial and isodiametric on head, superficial and moderately to barely transverse on pronotal disc, superficial on elytra, but often coarse along elytral striae.

Head fairly small to medium-sized, without neck constriction, each side with two setae in a deep supra-ocular groove. Eyes more dorsal than lateral in position, ranging from medium-sized and convex to small yet protruding so that genae are distinct to nearly indistinct, respectively. Frontal foveae sulciform and mostly smooth, very deep to fissurelike, short to very long. Clypeus bisetose, truncate apically, labrum subsinuate to bilobed at apical margin. Antennae short, pubescent from antennomere 4 onwards, antennomere 3 without additional setae.

Mandibles moderately long, without longitudinal scrobal sulcus. Mentum bisetose at base of a narrow, slightly bifid, sometimes blunt, median tooth (the setae missing in one species), with one pair of deep or very deep pits behind. Submentum bisetose (outer setae missing). Terminal palpomere broadened apicad, more so in labial than in maxillary palps, being mostly subfusiform to subtriangular in the former while subtriangular to triangular in the latter; fusiform in one species — the palpomere usually pentagonal rather than triangular due chiefly to straight inner margin and convex outer margin. Penultimate labial palpomere 3-4-setose owing to 1-2 latero-apical setae additional to two fixed setae.

Pronotum subquadrate to cordiform, with a thick lateral bead; lateral groove with two setae, anterolateral and posterolateral, the latter just inside basal angle. Base conspicuously sinuate, basal angles subrectangular, blunt to obtuse and rounded. Lateral groove deep, narrow and impunctate to very wide and densely punctate, reaching both base and apex. Either inner or outer basal sulcus, or both obliterate; inner sulcus varying from long to totally reduced, outer sulcus short, impunctate, running very close to or merging into lateral groove; area between inner sulcus and outer one without basal foveae and mostly impunctate. Median line almost entire, fine to sulcate and very deep. Basal and apical transverse impressions missing; basal bead missing or traceable only outside inner basal sulcus; apical bead obliterate in middle third to almost entirely.

Elytra connate, elliptic, broadest at or just behind the middle, with faint or no preapical sinuation; apices contiguous and rounded combined. Base fairly narrow; humeri more or less distinct, toothed or not; basal ridge from entire, distinct between stria 1 and humerus, to obliterate inside stria 3 . Inner preapical plica slightly to totally reduced, not quite reaching lateral ridge and thence invisible in lateral view in specimens with interlocked abdomen and elytra. Striae deep or very deep, impunctate to conspicuously punctate, often broadened apicad and grooved before apex. Intervals convex to costate, often (sub)carinate apically. Interval 8 as wide as to much narrower than 7 th. Parascutellar striole vestigial or totally reduced. Parascutellar seta present, interval 3 without setigerous pores, sometimes with one pore (d2) adjoining stria 2 at or behind the middle. Stria 7 with 1-2 (mostly one, anterior) preapical setigerous pore. Umbilical seta series (USS) continuous, consisting of 15-28 setae.

Underside: Prosternum in basal three quarters without or with a distinct medial groove; prosternal process not beaded, hexagonal, with apical angles sharp to rounded; apical declivity flat to convex. Mesoventrite without precoxal tubercle. Metepisternum short, as long as or barely longer than wide. Abdominal sternites laterally beaded, with one pair of obligatory setae, sternite VII not or barely modified in male, bisetose in both sexes. Underside smooth, but mesepisternum in basal half (or only its oblique median concavity) and sometimes also metepisterna rather sparsely and moderately to coarsely punctate.

Legs rather strong. Protibia ( $t i 1)$ dilated apicad, with slightly lobate latero-apical angle, one spinule at apex of posterointernal ridge, and 3-7 apical spinules at posterolateral ridge; the apical spinules being continuous or proximal spinule slightly separated. Metatrochanter about half as long as metafemur, more or less tapered apicad, with blunt tip. Meso- and metatarsi without (eastern species) or with (western species) outer longitudinal carina or sulci. Profemur $(f e l)$ with three posterior setae (basal, medioventral, and preapical) or two (basal seta missing); mesofemur with two equally spaced anteroventral setae and two anterodorsal setae in apical half; metacoxa bisetose (inner seta reduced), metatrochanter asetose, metafemur bisetose. Metatibia asetose at outer margin. Tarsomere 5 (tm5) setose or glabrous ventrally. Tarsomeres 1-4 each with one pair of latero-apical setae (LAS), tarsomeres 1-3 each with one pair of dorso-apical setae (DAS).

Aedeagus (Figs 10-39) geniculate in general; right paramere long to short. Everted and inflated internal sac with a fairly strong apical sclerite (in examined species).

Female genitalia (Figs 41-43, 45-48) and reproductive tract. Gonostyli stout. Gonosubcoxite glabrous, slightly desclerotized at base of inner margin. Gonocoxite claw-like, about half as long as gonocoxite, with apex pointed to blunt and 2 4 , mostly two, very strong and long outer ensiform setae; neither inner (dorsal) setae nor apical setae retained. Spermathecal basal sclerite missing (or at least lightly pigmented); seminal canal serpentine and more or less long, terminating in a cylindrical recurved receptaculum; spermathecal gland duct enters this curve.

Secondary sexual differences: Males are distinctive in having protarsomeres $1-3$ dilated, with adhesive ventral scales; mesotibiae with a few minute preapical tubercles at almost indistinctly angulate inner margin; metatibia sometimes slightly tuberculate along postero-internal ridge. In females, mesoand metatibiae internally smooth, flat or convex. 

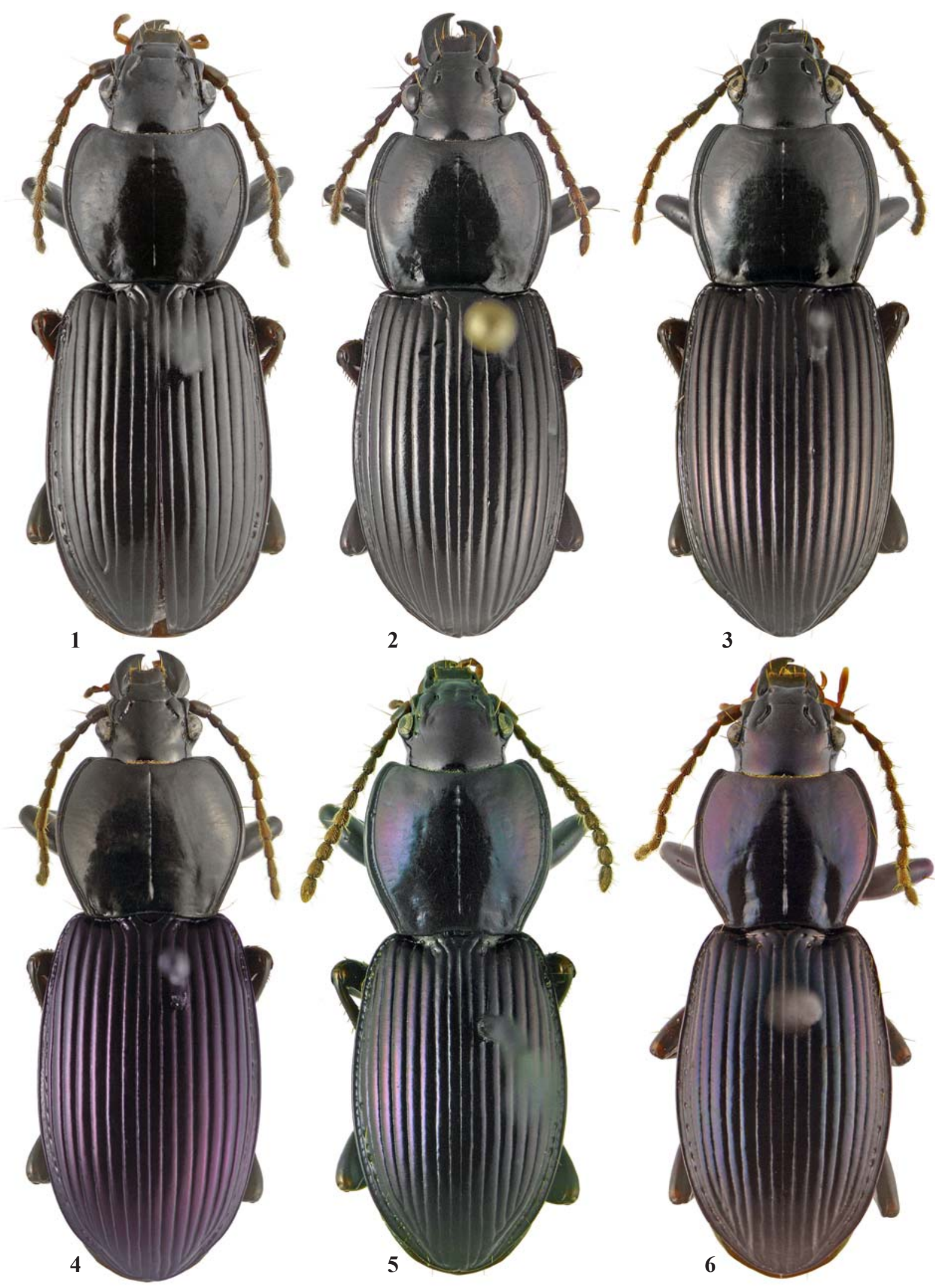

Figs 1-6. Dorsal habitus: 1 - Pterostichus obliteratus sp.n.; $2-P$. asulcatus sp.n.; $3-P$. kataevi sp.n.; $4-P$. glymmiger; $5-P$. violaceus; $6-P$. pseudoviolaceus sp.n.

Рис. 1-6. Габитус дорзально: 1 - Pterostichus obliteratus sp.n.; 2 - P. asulcatus sp.n.; 3 - P. kataevi sp.n.; 4 - P. glymmiger; $5-$ P. violaceus; 6 - P. pseudoviolaceus sp.n. 
DIAGNOSIS. Distinctive chiefly in the following points: Body medium-sized. Terminal labial palpomere predominantly triangular, more so in male than in female; penultimate labial palpomere bisetose to quadrisetose, i.e., with 1-2 additional latero-apical setae in the latter case; mentum tooth triangular, narrow and bifid apically. Antennae short, not reaching pronotal base. Frontal foveae sulciform and deep or very so. Eyes dorsolateral, fairly small, and convex to protruding. Pronotum bisetose on each side, without or with one, inner or outer, distinct basal sulcus; disc separated by a fairly narrow lateral groove from thick lateral bead. Elytra connate, elliptic, with sutural angles contiguous and right; preapical sinuation fairly deep to missing, with internal plica well-developed to indistinct, respectively. Parascutellar striole short or missing; parascutellar seta present; interval 3 asetose, sometimes with seta d2 adjoining stria 2 ; metepisterna short following apterous condition. Abdominal sternite VII bisetose in both sexes. Legs: $\mathrm{fel}$ with posterobasal seta missing in most species, leg chetotaxy otherwise as in many advanced lineages of Pterostichus: mesotibia 2+2-setose anteriorly, metacoxa bisetose (inner seta missing), metatrochanter asetose, metatibia bisetose; tarsomere 5 without or with ventral setae. Meso- and metatarsi mostly without outer carinae or sulci, more rarely with either. Aedeagus strongly curved at base or geniculate, everted and inflated internal sac bent to the left and then ventrad; left paramere as for the genus.

DISTRIBUTION. Eastern India (Assam, Manipur, and Meghalaya States), Bhutan, Myanmar, Thailand (Chiangmai Province), southern China (Yunnan and Fujian Provinces),
Vietnam (Lao Cai, Dien Bien, Kon Tum, Gia Lai, Dak Lak, and Lam Dong Provinces). The species of the genus are known to be allopatric, piedmont to mid-montane; all have fairly restricted species ranges. Pterostichus sulcatipennis sp.n. and $P$. pseudoviolaceus sp.n. are only known to cooccur in the Ngoc Linh Mts in Central Vietnam; P. glymmiger (Andrewes, 1937) and P. obliteratus sp.n. from northern Vietnam appear to be a similar couple.

HABITATS AND HABITS. In Vietnam, adult Steropanus inhabit monsoon broad-leaved and mixed forests at 900-2000 m elevations, dwelling in leaf-litter as well as in the soil. Their rather pedunculate bodies, strong legs, and apically much dilated protibiae with well-developed spiny armature, apparently reflect subterranean habits. Body integuments mudded in many examined specimens of $P$. foveifrons sp.n. argue for the surmise.

COMMENTS. Tritrichis was erected as the genus separate from Pterostichus, based on the labial palps distinctive, with the apical palpomere "dilated in the $\sigma^{\text {z' }}$ ( $v s$. fusiform) and the penultimate palpomere bearing one or more setae additional to two fixed setae ( $v s$. no additional setae). The two characters, along with short labial palps, very deep frontal furrows, small and prominent eyes, and similar tarsal chetotaxy (LAS and DAS), are observed also in Myas Sturm, 1826 subgenus Trigonognatha Motschulsky, 1858. On the other hand, Myas is very different, especially as regards its distinctive aedeagus, including right paramere, whereas that of Steropanus is typical of Pterostichus.

Out of the examined subgenera of Pterostichus, Orientostichus is most similar to Steropanus in subtriangular terminal
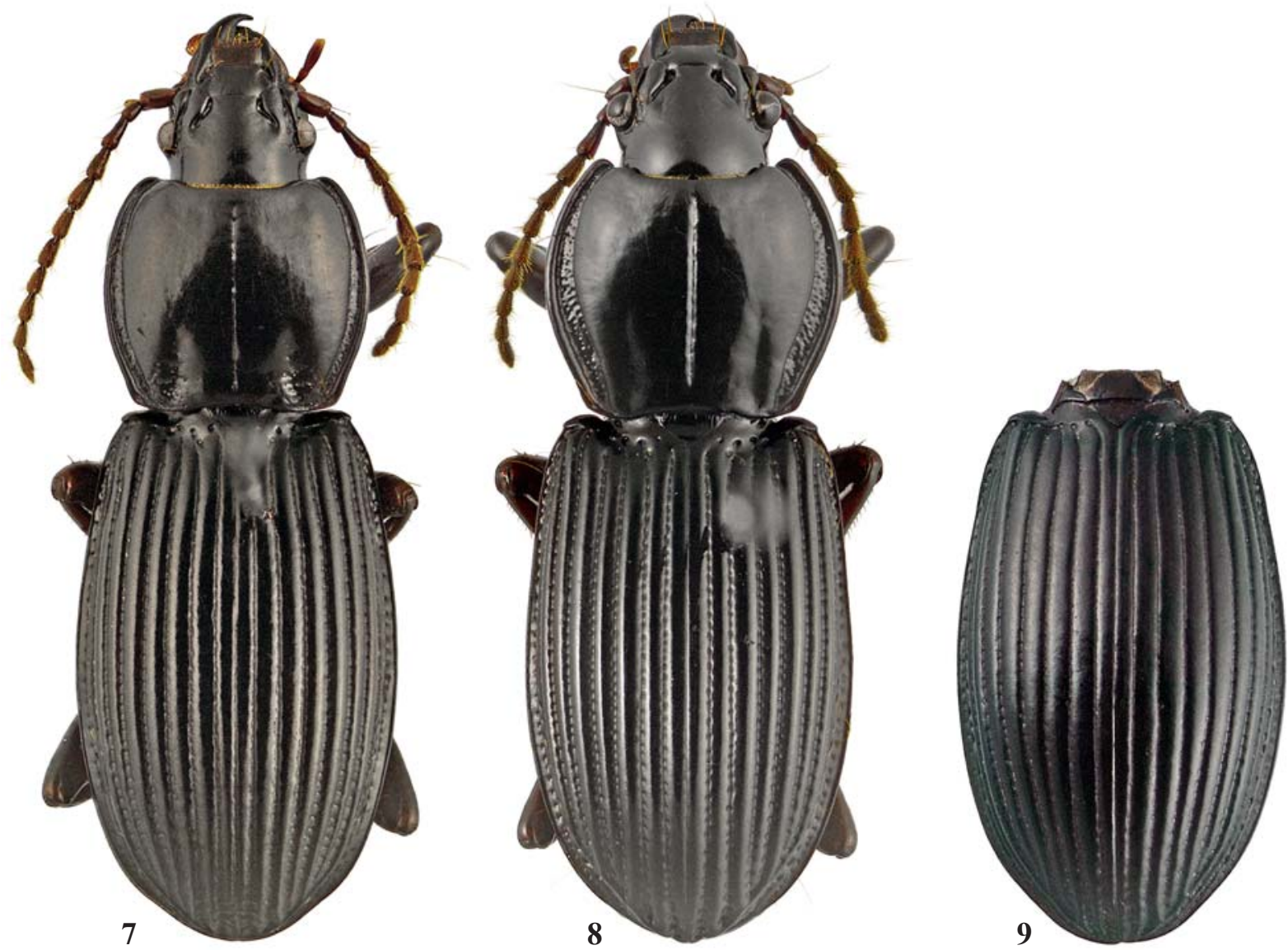

Figs 7-9. Dorsal habitus: 7 - Pterostichus sulcatipennis sp.n.; $8-P$. cavifrons sp.n.; 9 - P. alveolatus sp.n.

Рис. 7-9. Габитус дорзально: 7 - Pterostichus sulcatipennis sp.n.; 8 - P. cavifrons sp.n.; 9 - P. alveolatus sp.n. 
labial palpomere and tarsal chetotaxy. Pseudethira Sciaky, 1996 is only different from Steropanus in having apical labial palpomere fusiform and no additional setae on the penultimate labial palpomere. Many other characters vary greatly between species and between species groups of Pseudethira. In particular, the body colour ranges from black to metallic, elytral discal setae from 0 to 4 , parascutellar striole from long to missing, parascutellar seta from present to absent, and tarsomere 5 from glabrous to setose ventrally; these or those just listed character states are observed in Steropanus as well. Otherwise the subgenus is very similar to Steropanus: the eyes are often small and prominent and the pronotum is similar, with no explanate lateral margin other than a fine lateral bead. Inner basal pronotal sulcus is only well-developed, with the outer one being reduced completely or to a vestigial angulate stria running close to basal angles in some species, e.g., P. gagates (Hope, 1831). The atroxgroup [Schmidt, 2006, 2012] of Pseudethira is most similar to Steropanus in the elytral discal setae wanting and the abdominal sternite VII bisetose in both sexes. Female reproductive tract and styli (compare Figs 42-49) are very similar in the two subgenera as well. Finally, the ranges of Ethira Andrewes, 1936, Pseudethira and Steropanus are vicariant and succeed each other from the west to the east. This suggests that Pseudethira may be the closest ally of Steropanus.

All the species of Steropanus could be arranged into two rather formal-groups defined by tarsomere 5 being either setose or glabrous ventrally. The setose tarsomere differentiates the western and northern species (five from India, Myanmar and Thailand; one species from northern Vietnam) from the other consubgeners that are eastern in distribution, ranging between southern China and southern Vietnam. Of these latter species, five more southern ones ( $P$. pseudoviolaceus sp.n., $P$. sulcatipennis sp.n., $P$. alveolatus sp.n., $P$. foveifrons sp.n., and $P$. violaceus (Straneo, 1949)) are certain to be more closely related inter se.

According to the description, Tritrichis chinensis Jedlička, 1962 is very distinctive in having the pronotum widely explanate on sides, pronotal basal foveae large and rounded, and the elytra with long parascutellar striole and apices rounded separately each. This character combination is uncharacteristic of Steropanus and suggests the placement of $P$. chinensis in or near Orientostichus.

Key to SPECIES of STEROPANUS.

1(6) Elytral interval 3 with one seta at or behind the middle.

2(3) Elytral striae distinctly punctate behind the middle, becoming wide and shallow grooves before apex, with subcarinate intervals in between. Elytra black; discal seta just behind the middle. BL $\sim 13.5 \mathrm{~mm}$. - Central Vietnam 9. P. alveolatus sp.n.

3(2) Elytral striae impunctate. Body black, elytra with metallic tinge. Tarsomere 5 setose ventrally. Pronotum with inner basal sulcus long, reaching the middle or almost so.

4(5) Elytra purplish, with humeral teeth. Sides of pronotum rounded in basal half, basal angle as a sharp right tooth. BL 16 mm. - Myanmar ..... P. felix (Andrewes, 1937)

5(4) Elytra with violaceous tinge, without humeral teeth. Sides of pronotum straight in front of right basal angles. BL $14.8 \mathrm{~mm}$. - Northwestern Thailand (Chiangmai) .. P. thailandicus (Straneo, 1989)

6(1) Elytral interval 3 asetose (exceptionally with one unilateral seta a third from apex).

7(14) Tarsomere 5 setose ventrally. Pronotum without outer basal sulcus.

8(11) Pronotum with inner basal sulcus distinct in basal $1 / 2$ $1 / 3$; basal angles sharp.
9(10) Sides of pronotum rounded in basal half, basal angles in form of a sharp right tooth. Elytral striae deep and impunctate. Body black and smaller, BL 14.5-15.5 mm. India (Manipur) ........... P. deliciatus (Andrewes, 1937)

10(9) Sides of pronotum gently sinuate in front of obtuse yet sharp basal angles. Elytral striae very deep and impunctate or very finely punctate. Body black, without or with violaceous tinge on elytra, and larger, BL 17.5-18.5 mm. India (Assam, Meghalaya); Bhutan

P. infissus (Andrewes, 1937)

11(8) Pronotum with inner basal sulcus obliterate or hardly traceable; basal angles very obtuse to rounded.

12(13) Body violaceous and larger, BL $17-17.5 \mathrm{~mm}$. Pronotal basal angles highly obtuse. Elytral intervals convex, 3rd and 7 th carinate before apex. - Thailand ....

$$
\text { P. thailandensis (Morvan, 1992) }
$$

13(12) Body black and smaller, BL 11.9-13.7 mm. Pronotal basal angles obtuse and rounded. Elytral intervals subconvex. - Northern Vietnam ........... 1. P. obliteratus sp.n. 14(7) Tarsomere 5 glabrous ventrally.

15(20) Pronotum with a short yet distinct outer basal sulcus just inside lateral bead; inner basal sulcus very shallow to missing.

16(17) Body black and smaller, BL $15 \mathrm{~mm}$. Elytral striae impunctate, intervals gently convex.- Northern Vietnam P. aequus (Andrewes, 1937)

17(16) Body larger, BL 17.9-20.5 mm, black; elytra throughout or along sides dark violet or with faint violaceous tinge. Elytral intervals convex.

18(19) Elytra with striae impunctate and no humeral teeth. China (Yunnan) ................. P. mengtzei Jedlička, 1931

19(18) Elytron with striae subpunctate to nearly impunctate and a minute humeral tooth. - Northern Vietnam (Lao Cai) .

20(15) Pronotum without outer basal sulcus.

21(22) Pronotum with lateral groove widely sulcate, markedly wider than lateral bead, and densely punctate; median line sulciform; inner basal sulci moderately deep and smooth, almost reaching middle. Elytral striae deep, punctate, very deep before apex, with punctures medium-sized yet deeply foveate; intervals very convex, costate apically. Frontal sulci long, as deep cavities just behind clypeus, very deep behind. Body black. BL 12.6-14.7 mm. Central Vietnam ........................... 7. P. cavifrons sp.n.

22(21) Pronotal lateral groove not or barely wider than lateral bead, impunctate or very finely punctate. Body black or metallic violaceous.

23(24) Pronotal lateral groove as wide as or barely wider than lateral bead, finely punctate; inner basal sulcus deep, disappearing $2 / 5$ from base, nearly smooth to coarsely and densely punctate at bottom and around, mostly outside. Elytral striae deep and punctate, widely yet rather shallowly grooved before apex; intervals very convex, carinate apically. Frontal sulci very deep. Body black. BL 15.3-17.7 mm. - Central Vietnam .......... 6. P. sulcatipennis sp.n.

24(23) Pronotal lateral groove very narrow.

25(28) Dorsum bright violaceous; body small, BL 9.8-11.7 $\mathrm{mm}$. Pronotum subcordate, with sides gently sinuate in front of obtuse or subrectangular basal angles; lateral groove faintly crenulate at bottom. Elytral humeral tooth indistinct.

26(27) Pronotum with inner basal sulci obliterate or hardly traceable. Frontal sulci long, reaching the level of posterior supra-ocular seta. Mentum asetose. Elytral striae thin, intervals subequally convex and subequally wide; inner striae minutely or indistinctly punctate at bottom; stria 7 
with two preapical setae; stria 9 conspicuously punctate, rather coarsely in basal third. Elytral basal ridge outside stria 3. BL 9.8-11.1 mm. - Southern Vietnam (Dalat Plateau) 8. P. violaceus

27(26) Pronotum with inner basal sulci deep. Frontal sulci short, reaching the level of anterior supra-ocular seta. Mentum bisetose. Elytral striae mostly impunctate, distinctly broadened and coarsely microsculptured before apex; intervals carinate apically, with $3 \mathrm{rd}$, 5th and 7th distinctly broader than others; stria 7 with single preapical seta; stria 9 smooth or vaguely punctate behind humerus. Elytral basal ridge entire. BL 10.7-11.7 mm. Central Vietnam (Northern Kon Tum)

5. P. pseudoviolaceus sp.n.

28(25) Body either black or larger, elytra sometimes dark violaceous. Sides of pronotum rounded in basal half; lateral groove smooth. Frontal sulci short.
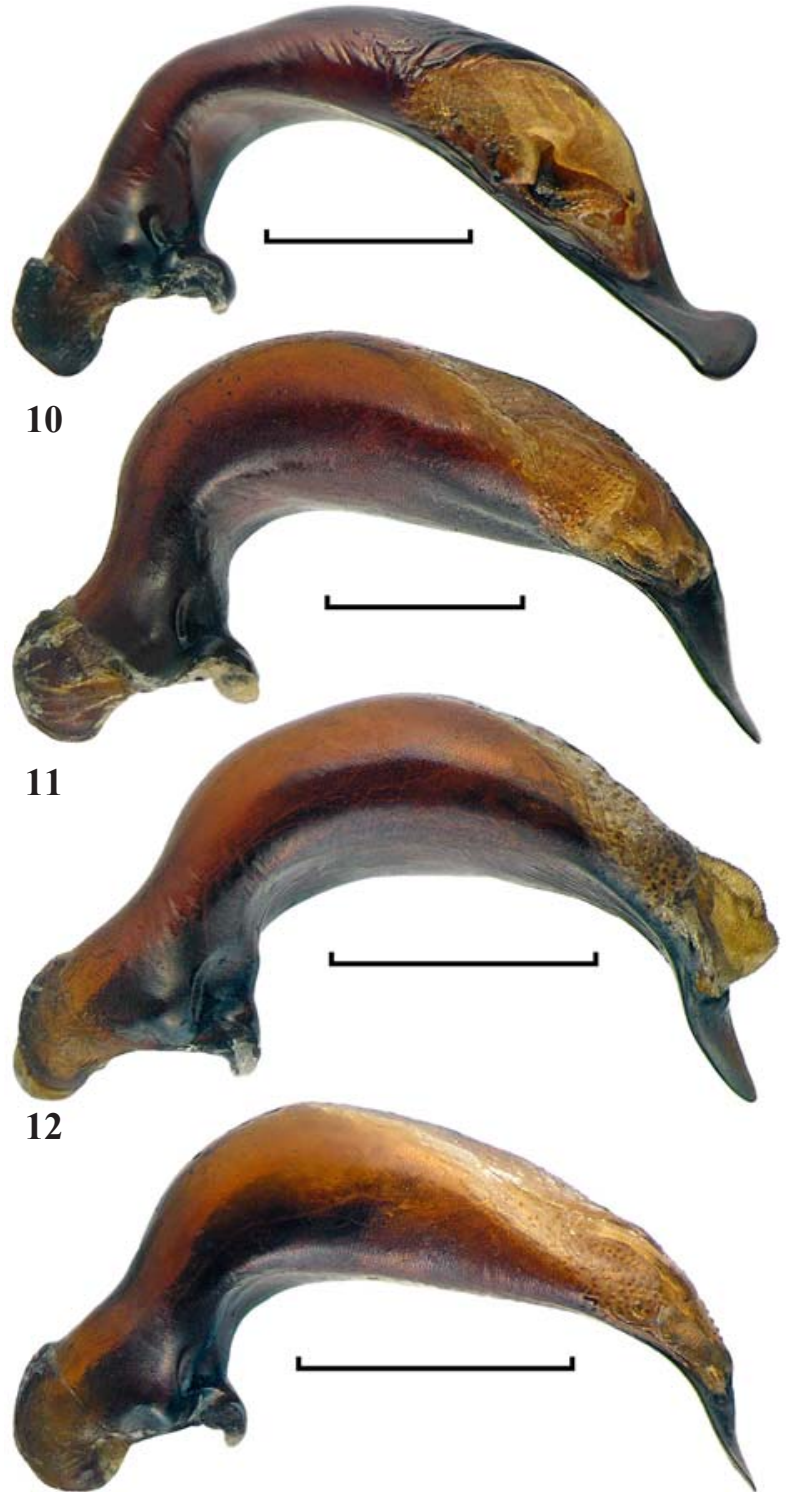

13
29(30) Body small, BL 11.5-12.9 mm, and black. Elytra about half longer than wide. Pronotum with shallow inner basal sulci and vestigial outer ones. - China (Yunnan) P. forticornis (Fairmaire, 1889)

30(29) Body large, $\mathrm{BL} \sim 17-19 \mathrm{~mm}$. Elytra three fifths longer than wide. Pronotum without basal sulci.

31(32) Body barely larger, BL 17.8-18.9 mm, and black; elytra dark violaceous. Elytral striae minutely punctate at bottom. Frontal sulci running parallel behind clypeus, then strongly and smoothly curved outwards, subequally very deep throughout. Elytral microsculpture slightly transverse. Northern Vietnam (Dien Bien) ....... 3. P. asulcatus sp.n.

32(31) Body a bit smaller, BL $16.9 \mathrm{~mm}$, and black. Elytral striae smooth. Frontal sulci slightly shortened from behind and thence slightly curved outwards. Elytral microsculpture nearly isodiametric. - China (Yunnan) 4. P. kataevi sp.n.
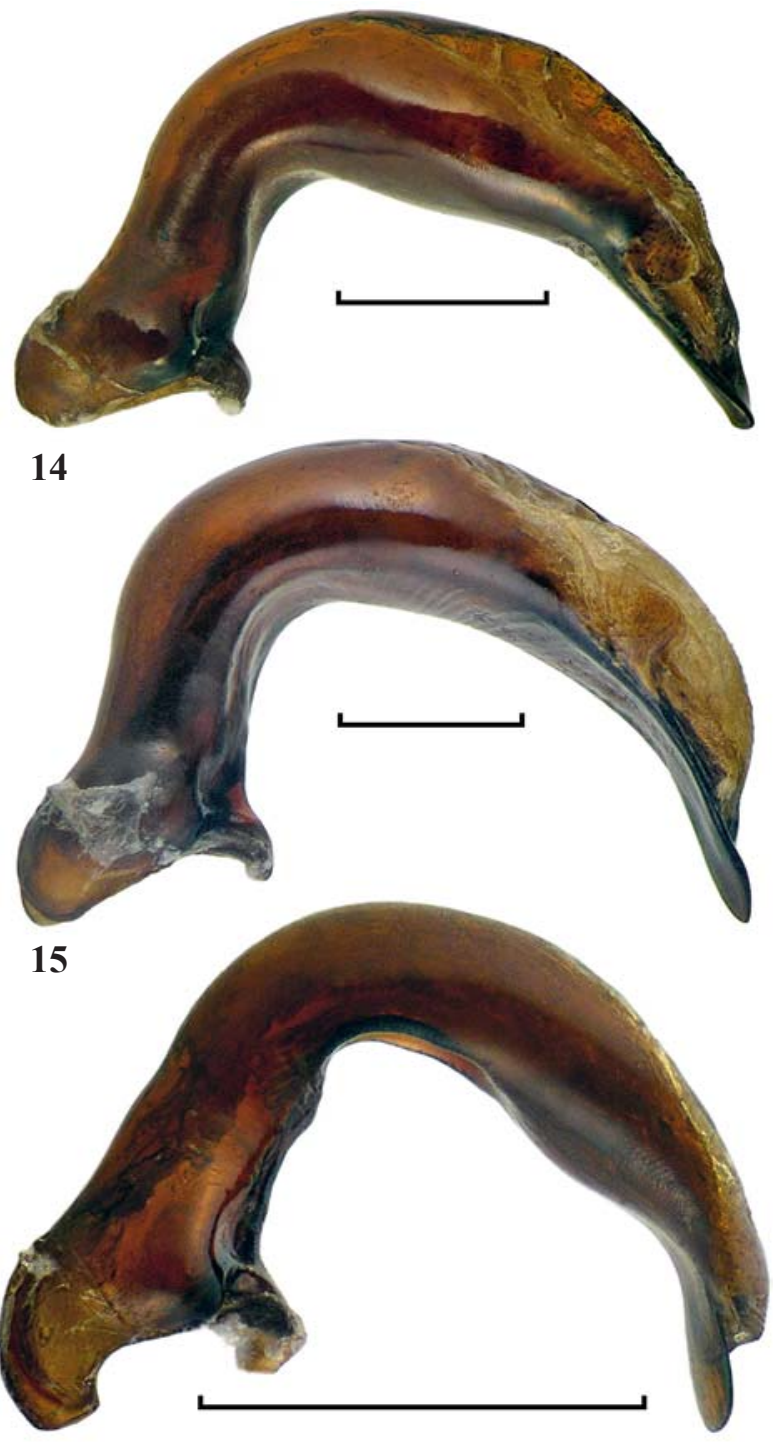

16

Figs 10-16. Median lobe of aedeagus, left aspect: 10 - Pterostichus obliteratus sp.n.; $11-$ P. sulcatipennis sp.n.; $12-$ P. cavifrons sp.n.; $13-P$. pseudoviolaceus sp.n.; $14-P$. asulcatus sp.n.; $15-$ P. glymmiger; $16-P$. violaceus. Scale bars $1 \mathrm{~mm}$.

Рис. 10-16. Средняя доля эдеагуса, вид слева: 10 - Pterostichus obliteratus sp.n.; $11-$ P. sulcatipennis sp.n.; $12-$ P. cavifrons sp.n.; $13-P$. pseudoviolaceus sp.n.; $14-P$. asulcatus sp.n.; $15-$ P. glymmiger; $16-$ P. violaceus. Масштаб 1 мм. 


\section{Pterostichus (Steropanus) obliteratus}

Fedorenko, sp.n.

Figs 1, 10, 17, 26-27, 32, 41.

MATERIAL. Holotype $\sigma^{7}$ (ZMMU) labelled: 'N Vietnam, Lao Cai Prov[ince]., Hoang Lien Son Mt. ridge, env. Fansipan [Phang Xi Pang] Mt, Tram Ton, $\mathrm{h}=1950-2100$ [m], 15-30.VII.2007, leg. D.Fedorenko'. Paratypes (SIEE), $0^{\top}, 2$, $9+$, same data; $20^{\top} \sigma^{\top}, 5$ 우, same data, but 'pitfall traps, V-VI.2006, leg. A.Anichkin'.

DESCRIPTION. Body (Fig. 1) shiny black, BL 9.8-11.1 $\mathrm{mm}$. Antennomeres 5-11 mostly reddish along dorsal and ventral ridges, sometimes black. Tibiae towards apices and tarsi reddish to deep red. Palpi red; apical palpomere somewhat infuscate, yellow in apical $1 / 3-2 / 5$. Microsculpture hardly traceable or obsolete on head, very slightly transverse, traceable to obliterate, on pronotum, slightly transverse and distinct on elytra.

Eyes medium-sized, convex; gena long, about a third as long as eye, meeting neck at obtuse angle. Frontal sulci deep, long, diverging, slightly sinuose on a level with anterior supra-ocular seta and just before, terminating at this seta or extended to the level of posterior seta. Frons flat or barely convex, frons and vertex smooth or with several transverse wrinkles, and usually also with a very short and deep oblique impression, nearly pore, inside posterior supra-ocular seta.
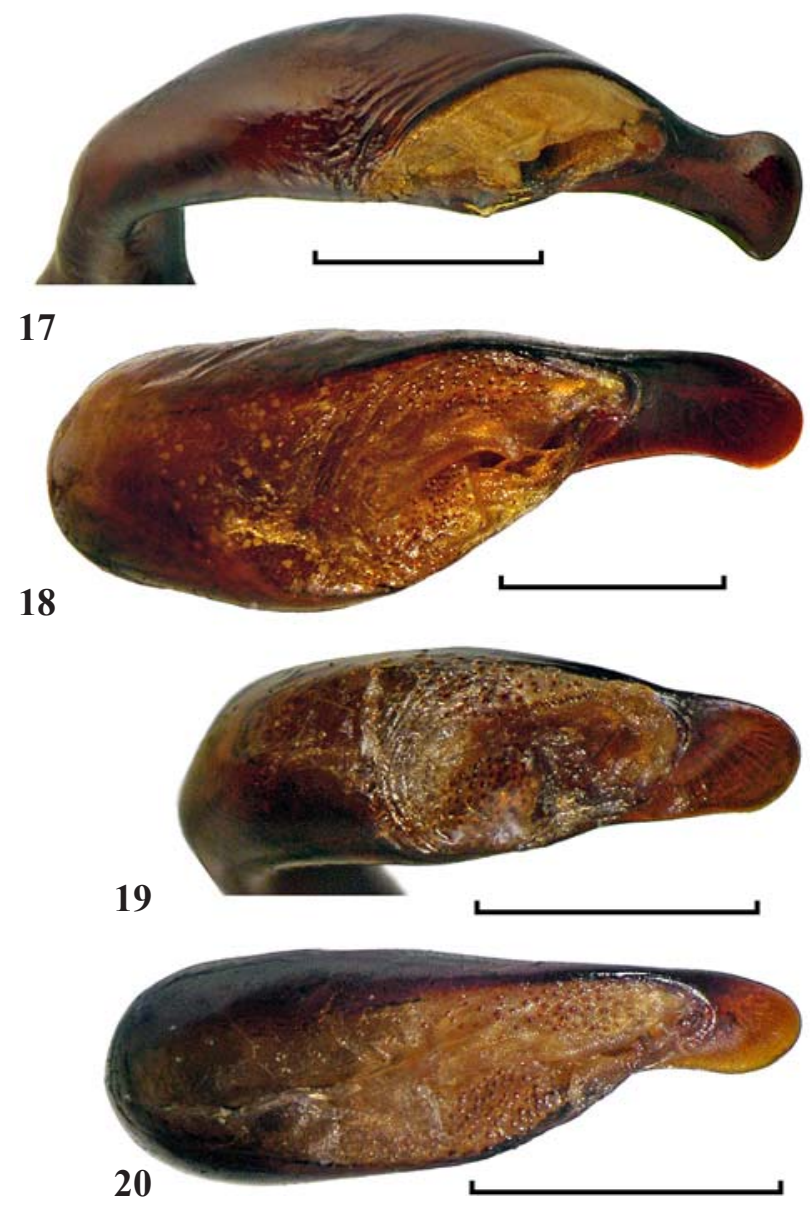

Labrum (sub)sinuate at apical margin, sexsetose; distance between outer two setae greater than between medial four setae. Antennae not quite reaching pronotal base.

Mandibles with large scrobes, dorsal scrobal ridge straight, ventral one convex, well-visible in dorsal view. Penultimate labial palpomere quadrisetose, with barely shorter additional setae; and a vestigial seta at apex of outer margin. Apical maxillary palpomere fusiform () or almost parallel-sided in apical half $\left(\sigma^{7}\right)$; apical labial palpomere slightly dilated, parallel-sided $\left(\bigcirc^{7}\right)$ or barely tapered in apical half $(+)$, with apex only a fourth $(+)$ or less than half $\left(O^{\gamma}\right)$ as long as inner margin.

Pronotum convex, subquadrate, PW/PL 1.22-1.30 (mean $1.26, \mathrm{n}=5)$, PW/HW 1.48-1.58 (1.53), rounded on sides, broadest just before middle, PLw/PL 0.43-0.45 (0.44); base truncate to slightly sinuate medially, slightly oblique towards very obtuse and rather widely rounded basal angles, narrower than apex, PWb/PWa 0.86-0.96 (0.91); apex evenly sinuate between slightly acute apical angles, finely beaded except medially. Lateral bead narrow and entire, lateral groove narrow, deep and indistinctly crenulate. Inner basal sulcus obliterate or vague; outer basal sulcus merged into lateral groove or retained as a short fine stria running along the groove just inside posterolateral seta and then extended slightly inside base. Disc sparsely transversely rugulose. Median line
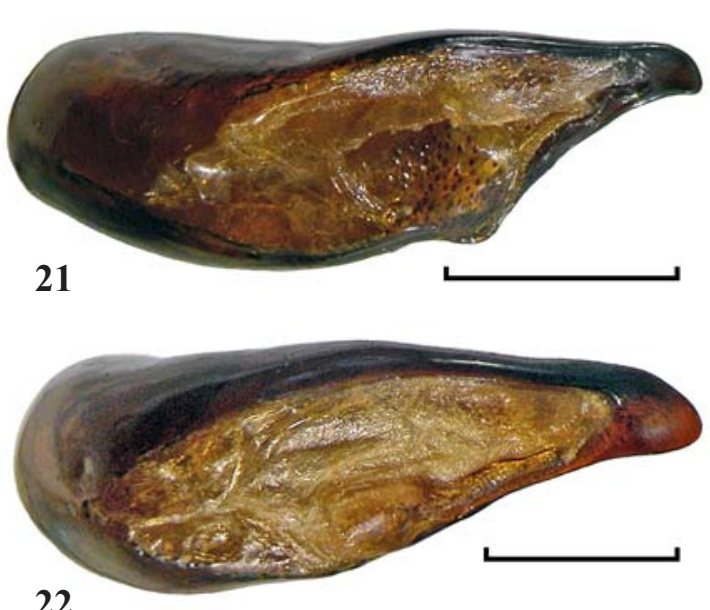

22

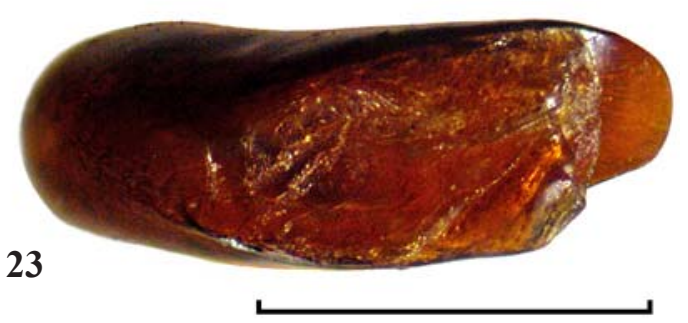

Figs 17-23. Median lobe of aedeagus in plane of apical lamella ( dorsal aspect): 17 - Pterostichus obliteratus sp.n.; $18-P$. sulcatipennis sp.n.; $19-$ P. cavifrons sp.n.; $20-$ P. pseudoviolaceus sp.n.; 21 - P. asulcatus sp.n.; $22-$ P. glymmiger;23 - P. violaceus. Scale bars $1 \mathrm{~mm}$.

Рис. 17-23. Средняя доля эдеагуса в плоскости вершинной ламеллы ( вид сверху): 17 — Pterostichus obliteratus sp.n.; 18 - P. sulcatipennis sp.n.; $19-$ P. cavifrons sp.n.; $20-$ P. pseudoviolaceus sp.n.; $21-$ P. asulcatus sp.n.; $22-P$. glymmiger; $23-$ P. violaceus. Масштаб 1 мм. 
fine, not quite reaching base and apex, deeper basally.

Elytra elliptic, EL/EW 1.52-1.58 (1.55), EW/PW 1.20 1.24 (1.22), broadest at about middle; base oblique, humeri rounded, without tooth, preapical sinuation indistinct, with very slightly reduced internal plica. Basal ridge entire, subtransverse, slightly sinuose, humeral angle obtuse or very so. Striae deep, impunctate. Intervals confluent apically in various combinations; 1st fused to lateral ridge at sutural angle, separated from intervals 2-8; outer intervals convex, inner ones slightly less so; 8th narrowly costate, distinctly to twice narrower than 7th, subcarinate just behind base and in apical quarter; interval 9 very narrow in basal two fifths. Reflexed lateral margin indistinctly broadened apicad (except in one specimen). Parascutellar setigerous pore close to stria 1 , parascutellar striole missing or very short. Discal setae missing. Stria 7 with single, anterior, preapical seta. USS consisting of 18-19 setae.

Underside. Prosternum in basal $1 / 2-3 / 5$ with very shallow to indistinct medial groove. Prosternal process in lateral view slightly projecting beyond procoxa and rounded, with apical angles rounded in ventral view. Abdominal sternites II-III often less distinctly beaded on sides; VII smooth in sexes. Mesepisternum moderately punctate in median oblique concavity, often with a few, mostly shallower, punctures in front; metepisternum and sides of metaventrite with sparser punctures.

Legs: $f e 1$ posteriorly trisetose, sometimes with posterobasal seta missing; til dilated apicad, its lateral edge sharp and slightly lobate at apical angle, mostly with four (rarely three) separate apical spinules. Tarsi laterally neither carinate nor sulcate; $t m 5$ setose ventrally.

Aedeagus (Figs 10, 17, 32): median lobe with ventral side straight in apical half, terminal lamella long and strongly dilated at apex. Right paramere moderately long, arcuate, rounded apically. Everted and inflated inner sac (Figs 26-27) with a very large apical sclerite and two preapical bulbs, left smaller than right.

Gonocoxite (Fig. 41) blunt at apex, with 3-4 ensiform setae.

DIAGNOSIS. Easily distinguishable from the consubgeners by the black body, tarsomere 5 setose ventrally, pronotum rounded on sides, with lateral groove narrow and inner basal sulcus vestigial to missing; elytra without humeral teeth and dorsal setigerous pores, elytral striae deep and impunctate.

DISTRIBUTION. The type locality only.

NAME. Refers to obliterate basal sulci of pronotum.

HABITATS AND HABITS. All specimens were taken by pitfall-traps in rainforests.

COMMENTS. This species shares the ventrally setose tarsomere 5 with consubgeners from India, Myanmar and Thailand, whereas all the species from China and Vietnam, except for $P$. obliteratus sp.n., are distinctive in having the glabrous tarsomere. On the other hand, very similar internal sacs of aedeagus suggest close relationship between $P$. obliteratus sp.n. and $P$. glymmiger.

\section{Pterostichus (Steropanus) glymmiger \\ (Andrewes, 1937)}

Figs 4, 15, 22, 24-25, 38.

in).

Andrewes, 1937: 490, 493 (Tritrichis; Chapa [=Sa Pa], Tonk-

MATERIAL. $3 \sigma^{7} \sigma^{7}$ (ZISP), Vietnam, Lao Cai Prov., Sa Pa Distr., Fan Si Pan [Phang Xi Pang] Mt., 1400-1500 m, 26.V.6.VI.1999, N.L.Orlov [leg.], $22^{\circ} 18^{\prime} 56^{\prime} \mathrm{N} 103^{\circ} 49^{\prime} 35^{\prime \prime} \mathrm{E}$; one of them with label 'Tritrichis glymmigera Andr., det. B. Kataev 1999'; 10' (ZISP), N Vietnam, Sapa env. 1500 m, 5.6.1999, Orlov.
REDESCRIPTION. Body (Fig. 4), BL 17.9-20.5 mm. Coloration as in the previous species, except for elytra entirely or along sides with rather faint violaceous tinge. Microsculpture superficial yet traceable on head, distinct and very slightly transverse on pronotum, same or barely more transverse on elytra.

Eyes medium-sized, convex; gena long, about a third as long as eye, meeting neck at obtuse angle. Frons and vertex smooth; a vague neck constriction traceable laterally. Frontal sulci deep, groove-like only just behind clypeus, then separating median part of frons from raised lateral parts; densely punctulate at bottom, strongly divergent and slightly curved outwards, terminating in front of anterior supra-ocular seta. Labrum sinuate, with rounded angles; distance between outer two setae greater than between medial four setae. Antennae not quite reaching pronotal base.

Penultimate labial palpomere trisetose at inner margin (posterior latero-apical seta missing), with short apical seta at outer margin. Apical palpomeres dilated apicad (in male); maxillary palpomere subtriangular, with apex slightly less than three fifths as long as inner margin; labial palpomere triangular, with apex as long as inner margin (not counting extreme base of the palpomere).

Pronotum convex, subcordate, PW/PL 1.26-1.27 (mean $1.27, \mathrm{n}=4)$, much broader than head, PW/HW 1.76-1.79 (1.78), broadest just before middle, PLw/PL 0.42-0.45 (0.43), sides rounded, indistinctly sinuate in front of basal angles; base sinuate medially, oblique towards obtuse basal angles, barely wider than apex, PWb/PWa 1.04-1.07 (1.06); apex sinuate while barely convex inside apical angles, finely beaded in lateral third. Apical angles slightly projecting, hardly more than right, with blunt tips. Lateral bead narrow and entire, lateral groove very narrow, deep and smooth. Inner basal sulcus vague yet (almost) reaching middle; outer sulcus as a short stria running close to lateral groove, with a fine costa between them, and then extended to inner basal sulcus, thereby forming a deep angulate stria in basal angle. Median line fine, not quite reaching base and apex, slightly deeper just in front of base, crenulate where crossed with vague transverse rugosities running over nearly smooth disc.

Elytra elliptic, EL/EW 1.63-1.67 (1.65), EW/PW 1.141.19 (1.17), broadest at about middle; base oblique, humeri rounded yet distinct, each with a small tooth; preapical sinuation faint, with much reduced internal plica. Basal ridge entire, subtransverse; humeral angle nearly indistinct. Striae deep, minutely punctate behind the middle, with inner three to five striae crenulate in basal half; sometimes all striae almost impunctate. Intervals convex before apex, slightly convex on disc, barely more convex laterally; 7th, 5th, 3rd and 2nd confluent apicad in succession; 1st fused to lateral edge in sutural angle and separated from 2nd; 8th distinctly narrower than 7th, narrowly costate in apical quarter, subcarinate just before single, anterior, preapical seta in stria 7, and again wide behind; interval 9 subequally wide throughout. Reflexed lateral margin slightly broadened apicad, a little uneven behind the middle. Parascutellar setigerous pore close to stria 1; parascutellar striole missing or vestigial (very short). Discal setae missing. USS consisting of 25-28 setae.

Underside. Prosternum in basal $1 / 2-3 / 5$ with nearly indistinct medial groove; prosternal process in lateral view slightly projecting beyond procoxa and rounded apically, with apical angles rounded in ventral view. Abdominal sternites conspicuously beaded on sides; male sternite VII faintly depressed in apical third between apical setae, with a very flat boss at middle of the depression and a minute tubercle close to apical bead. Mesepisternum densely and finely punctate in 
basal half; metepisternum and sides of metaventrite with sparser punctures.

Legs: $f e 1$ posteriorly bisetose (posterobasal seta missing); $t i 1$ as in previous species, except for 6-7 apical spinules.
Tarsi laterally neither carinate nor sulcate; tm5 glabrous ventrally.

Aedeagus (Figs 15, 22, 38): median lobe geniculate, with long basal part and the remainder evenly concave ventrally in
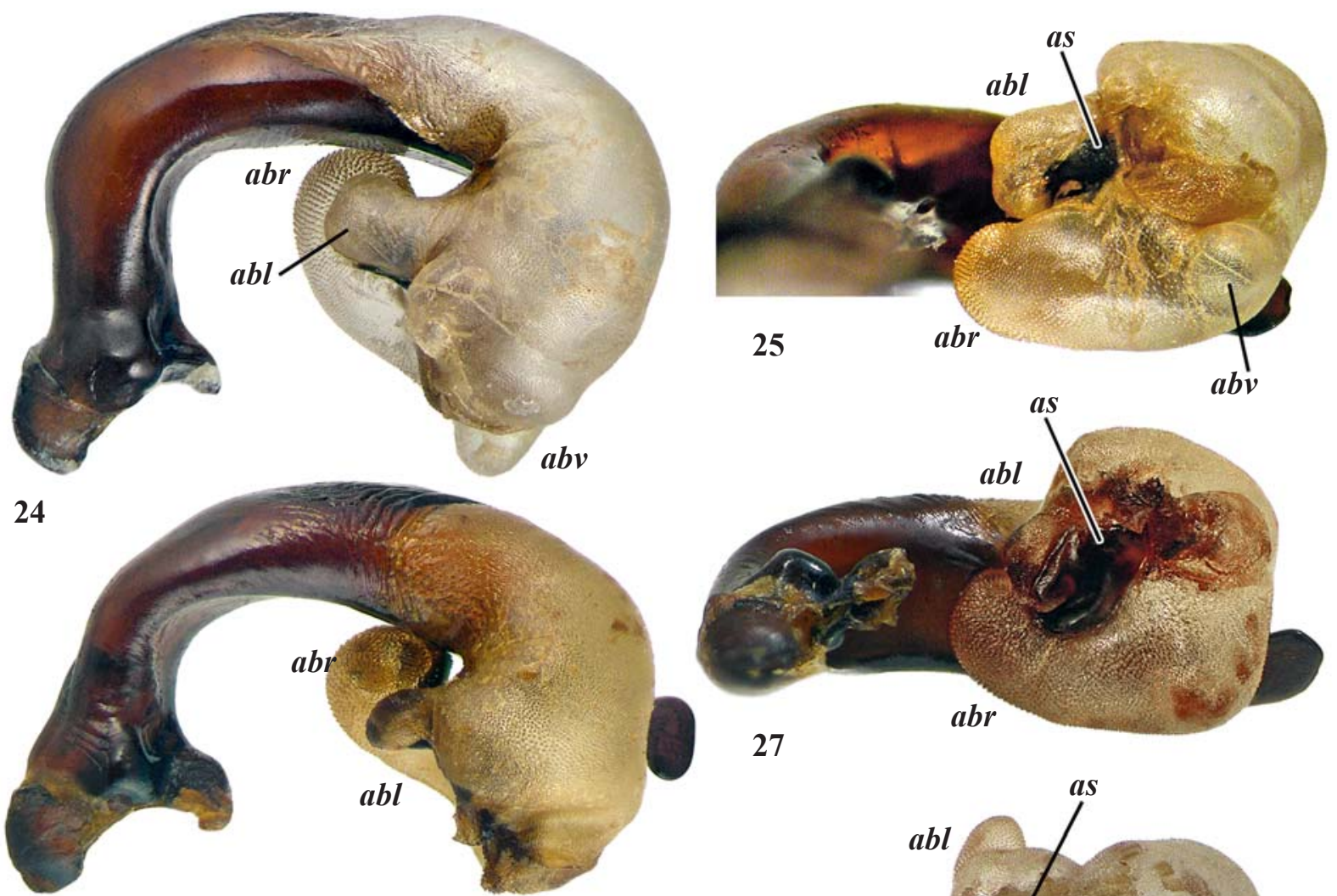

27

26

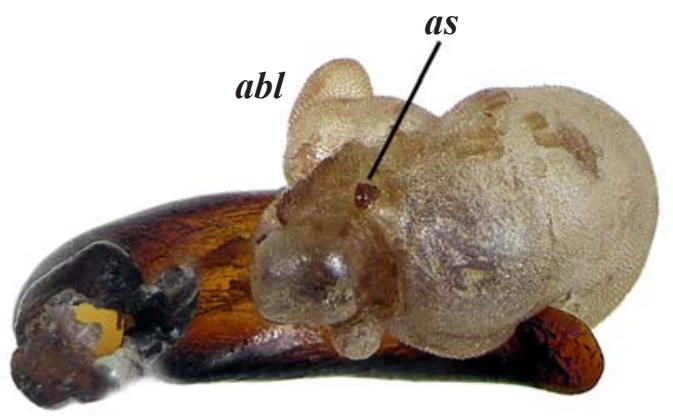

29

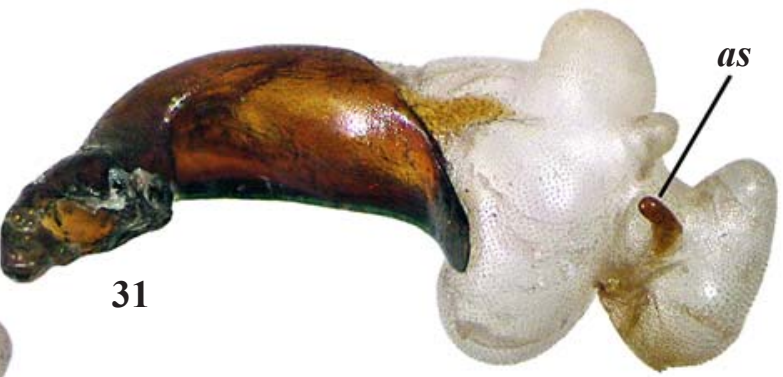

30

Figs 24-31. Everted and inflated internal sac of aedeagus: 24-25 - Pterostichus glymmiger; 26-27 - P. obliteratus sp.n.; 28-29 P. cavifrons sp.n.; 30-31 - P. violaceus; 24, 26, 28, 30 - left aspect; 25, 27, 29 - ventral aspect; 31 - left ventrolateral aspect; abl left apical bulb, $a b r$ - right apical bulb, $a b v$ - ventral apical bulb, as - apical sclerite.

Рис. 24-31. Вывернутый и надутый внутренний мешок эдеагуса: 24-25 — Pterostichus glymmiger; 26-27 - P. obliteratus sp.n.; 28-29 - P. cavifrons sp.n.; 30-31 - P. violaceus; 24, 26, 28, 30 - вид слева; 25, 27, 29 - снизу; 31 - слева и снизу; abl - левый апикальный пузырь, $a b r$ - правый апикальный пузырь, $a b v$ - вентральный апикальный пузырь, as - апикальный склерит. 
lateral view. Apex in dorsal view slightly curved to the left, with terminal lamella fairly short, subtriangular and narrowly rounded at apex. Right paramere long, slightly angulate a thirds from apex, with barely upturned apex. Everted and inflated internal sac (Figs 24-25) with a large apical sclerite and three preapical bulbs, fairly small ventral, very large right, and smaller left.

DISTRIBUTION. Known from the type locality only.

HABITATS AND HABITS. No data.

COMMENTS. According to the original descriptions, only finely punctate elytral striae differentiate $P$. glymmiger from $P$. mengtzei Jedlička, 1931 from the environs of Mengzi, southern Yunnan, China, this locality being about $130 \mathrm{~km}$ distant from the type locality of $P$. glymmiger. Later Jedlička [1962] noted also that $P$. mengtzei was distinctive in having no humeral tooth. My studies indicate that the two characters are little helpful for discriminating between the species because the characters vary to a certain degree in P. glymmiger.

Jedlička [1962] reported P. mengtzei also from Kuatun $(10 \mathrm{~km}$ NNW of Shaowu) in Fujian Province while noted that this beetle is smaller (BL 15-17.5 mm) than the female holotype. One could suppose from this difference and a very wide spatial gap between the two populations of $P$. mengtzei that the population from Fujian represents a separate and unnamed species.

\section{Pterostichus (Steropanus) asulcatus Fedorenko, sp.n.}

Figs 2, 14, 21, 39, 43 .

MATERIAL. Holotype $\sigma^{7}$ (ZMMU) and paratype + (SIEE) labelled: 'N-Vietnam, Dien Bien Prov[ince]., Muong Nhe Nat[ure] Reserve, $22^{\circ} 21^{\prime} 54^{\prime \prime} \mathrm{N} / 102^{\circ} 14^{\prime} 35^{\prime \prime} \mathrm{E}, \mathrm{h}=800 \mathrm{~m}$, Exped[ition] Russ[ia].-V[iet]n[am]. Tropic[al]. C[ente]r, 11-20.VI.2014, A.Abramov, A.Shchinov leg.'.

DESCRIPTION. As for the previous species, except as follows. Body (Fig. 2), BL 17.8-18.9 mm. Legs slightly darker, hind two leg pairs almost black. Head and pronotum with hardly traceable microsculpture.

Frons of the same level on each side of very deep and smooth frontal sulci. Neck constriction indistinct. Antennae reaching basal third of pronotum. Penultimate labial palpomere trisetose at inner margin (outer margin with apical seta traceable unilaterally in one of two specimens). Apical maxillary palpomere subtriangular $\left(\sigma^{7}\right)$ or subfusiform, with wide apex (+); apical labial palpomere triangular, with apex three fourths $\left(O^{7}\right)$ or half $(+)$ as long as inner margin.

Pronotum quadrate, PW/PL 1.23-1.29, PW/HW 1.66, broadest almost at middle, PLw/PL 0.47-0.49, evenly rounded on sides. Base wider, $\mathrm{PWb} / \mathrm{PWa} 1.15-1.16$; basal angles obtuse and blunt. Apical angles right. Lateral bead thick, becoming increasingly narrow just before base due to lateral groove gently curved outwards. Inner basal sulcus as small and vague impression in front of base; outer basal sulcus and basal bead inside it obliterate.

Elytra barely shorter, EL/EW 1.59-1.61, EW/PW 1.13-1.18, preapical sinuation distinct, with barely reduced internal preapical plica. Basal ridge outside stria 2 . Striae very gently broadened before apex, indistinctly punctate in basal half, very finely punctate behind. Intervals more convex, costate close to apex. Interval 3 without setae (with unilateral, right, seta $\mathrm{d} 2$ adjoining stria 2 in the holotype). USS consisting of 21-24 setae.

Underside. Male sternite VII in apical three fifths with a very flat median boss and a faint depression around. Mesepisternum in basal half rather densely yet shallowly punctate or very so; metepisternum and sides of metaventrite nearly impunctate.
Legs: til with a preapical spinule and two close apical spinules.

Aedeagus (Figs 14, 21, 39): median lobe with long basal part; ventral side subconvex in middle third, barely curved ventrad in apical third. Terminal lamella as in P. glymmiger yet smaller. Right paramere long, tapered apicad, slightly clavate, wit a little upturned apex.

Gonocoxite (Fig. 43) rounded apically, with 3-4 ensiform setae.

DIAGNOSIS. See description of the species.

DISTRIBUTION. The type locality only.

NAME. Refers to totally reduced pronotal basal sulci.

HABITATS AND HABITS. No data.

\section{Pterostichus (Steropanus) kataevi Fedorenko, sp.n.}

Figs 3, 42 .

MATERIAL. Holotype 9 (ZISP) labelled: 'CH[ina], Yunnan, Jinping, Shilicun Forest Station, $1960 \mathrm{~m}, 22^{\circ} 46^{\prime} 28.4^{\prime \prime} \mathrm{N}$ $103^{\circ} 17^{\prime} 49.3^{\prime \prime E}$, 16.XII.2003, B. Kataev leg. (5)', '? Steropanus forticornis Fairm.' [hw]

DESCRIPTION. As for P. asulcatus sp.n. except as follows: Body black (Fig. 3), barely smaller, BL $16.9 \mathrm{~mm}$. Elytral microsculpture less transverse, nearly isodiametric.

Gena very short, only a fifth as long as eye. Frontal sulci shortened from behind, running parallel just behind clypeus, then only slightly curved outwards. Penultimate labial palpomere without apical seta at outer margin.

$\mathrm{PW} / \mathrm{PL} 1.26, \mathrm{PW} / \mathrm{HW}$ 1.66, PLw/PL 0.44, PWb/PWa 1.14. Apex indistinctly convex inside apical angles. Basal angles slightly more rounded. Lateral groove straight posteriorly. Basal sulci and basal bead obliterate.

EL/EW 1.60, EW/PW 1.16. Preapical sinuation distinct, internal plica almost indistinct in lateral view. Striae largely impunctate, except for extremely fine and vague punctures. Stria 2 with unilateral (right) seta a third from apex. USS 21.

Gonocoxite (Fig. 42) pointed at tip, with three ensiform setae.

DIAGNOSIS. See the description.

DISTRIBUTION. Known from the type locality only.

NAME. Given after Dr. B.M. Kataev, expert in carabid beetles, especially Harpalini, my good friend, collector of the species.

HABITATS AND HABITS. No data.

COMMENTS. This species is hardly different from $P$. asulcatus sp.n. and may only be its subspecies.

\section{Pterostichus (Steropanus) pseudoviolaceus Fedorenko, sp.n.}

Figs 6, 13, 20, 34, 46.

MATERIAL. Holotype $\sigma^{7}$ (ZMMU) and paratypes, $\sigma^{\top}, 2$ 우 (SIEE), labelled 'Vietnam, Kon Tum Prov[ince], 2-3 km W of Ngoc Linh Mt., $15^{\circ} 05^{\top} \mathrm{N}, 107^{\circ} 57^{\prime} \mathrm{E}, \mathrm{h}=1600-2150 \mathrm{~m}$, pitfall traps, 19 .IIIIV.2006, leg. A. Anichkin'; paratypes 2 우 (ZISP) labelled 'Central Highlands, 2-3 km W of Ngoc Linh Mt. $15^{\circ} 05^{\prime} \mathrm{N}, 107^{\circ} 57^{\prime} \mathrm{E}, 1700$ 1900 m, 5.III-14.IV.2004, A.V. Abramov'.

DESCRIPTION. Body (Fig. 6), BL 15.8-18.2 mm, metallic violaceous. Underside and legs violaceous black. Antennae and tibiae toward apices reddish-brown, femoral apices, tarsi, palps, and antennomeres 5-11 red; terminal palpomeres somewhat infuscated while yellow in apical 2/3-1/ 2. Microsculpture superficial yet distinct, isodiametric on head and elytra, slightly transverse on pronotum; apically broadened elytral striae with coarse isodiametric meshes.

Eyes small and protruding; gena fairly long, almost two fifths as long as eye, meeting neck at highly obtuse angle. 
Frontal sulci smooth, very deep, slightly converging behind clypeus, then strongly diverging, terminating on a level with anterior supra-ocular seta. Labrum sinuate between widely rounded apical angles; apical setae subequally spaced. Antennae (almost) reaching pronotal base.

Penultimate labial palpomere with apical seta at outer margin, trisetose at inner margin (posterior latero-apical seta missing) to almost bisetose due to anterior latero-apical seta much reduced in size. Apical palpomeres fusiform in the sexes, except for labial palpomere barely dilated in male, with apex less than a third as long as inner margin.

Pronotum cordate, PW/PL 1.26-1.30 (mean 1.28, $\mathrm{n}=5$ ), PW/HW 1.42-1.55 (1.48), broadest two fifths from apex, PLw/PL 0.39-0.45 (0.41); sides rounded, barely to indistinctly sinuate just in front of basal angles. Base barely narrower than apex, PWb/PWa 0.90-0.96 (0.92), sinuate medially, oblique laterally; basal angles mostly obtuse, sometimes rounded.
Apex evenly sinuate or faintly convex inside slightly acute apical angles, finely beaded in lateral fourth. Lateral bead entire and narrow; lateral groove narrow, deep, smooth or crenulate at bottom. Inner basal sulcus impunctate, deep, deeper basally than apically, disappearing $1 / 3-2 / 5$ from base, obliterate just basally, slightly converging apicad, then running parallel to each other. Outer basal sulcus and basal bead missing. Median line deep, crenulate, mostly almost reaching base and apex. Disc smooth, faintly transversely rugulose.

Elytra elliptic, EL/EW 1.52-1.60 (1.55), EW/PW 1.17$1.22(1.20)$, broadest at about middle, with base somewhat oblique; humeri rounded, with teeth obsolete (traceable only when viewed in the plane of elytral epipleura). Sides rounded, with indistinct preapical sinuation. Basal ridge entire. Striae deep, smooth to very finely punctate at bottom, increasingly broadened apicad in apical 1/3-1/4, being as wide as intervals before apex. Intervals convex, carinate apically, 7th, 5th, 3rd
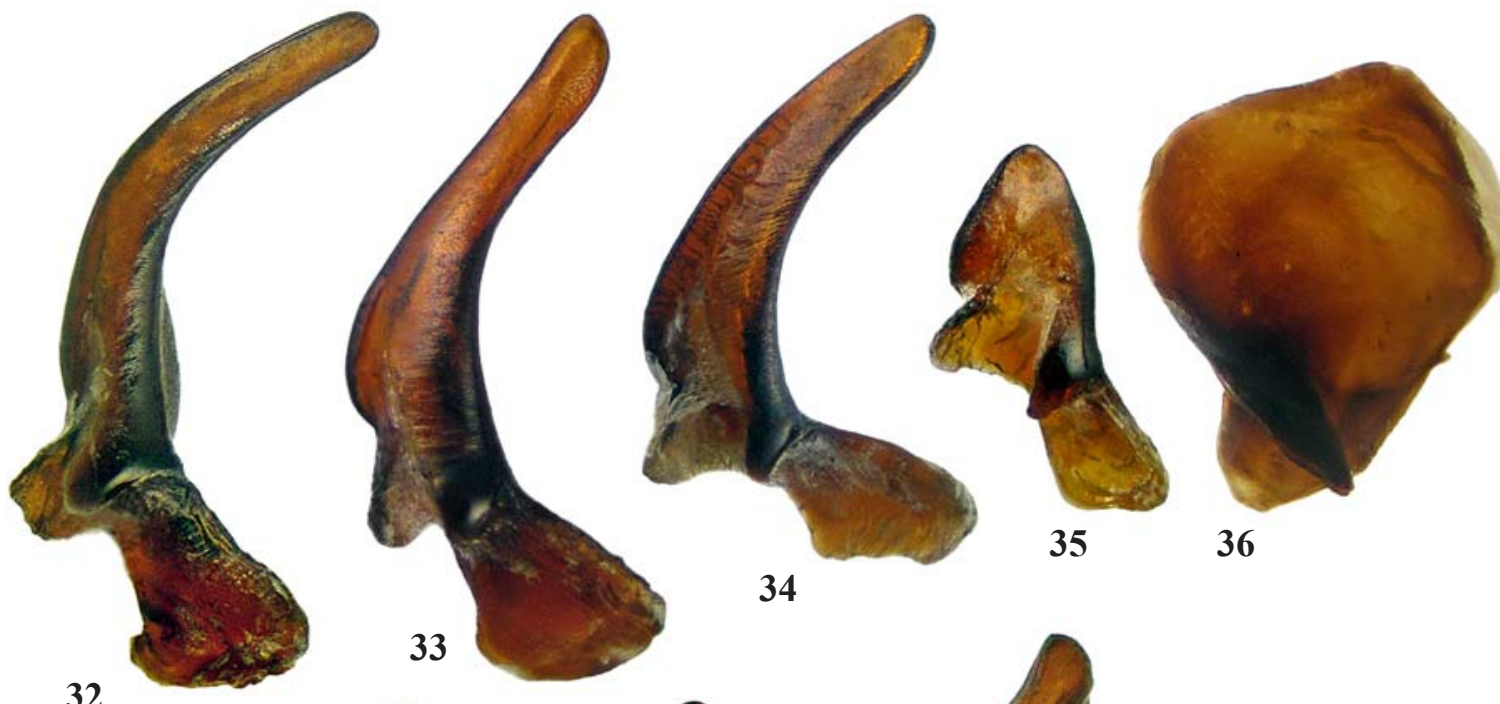

35

36

32

\section{4}
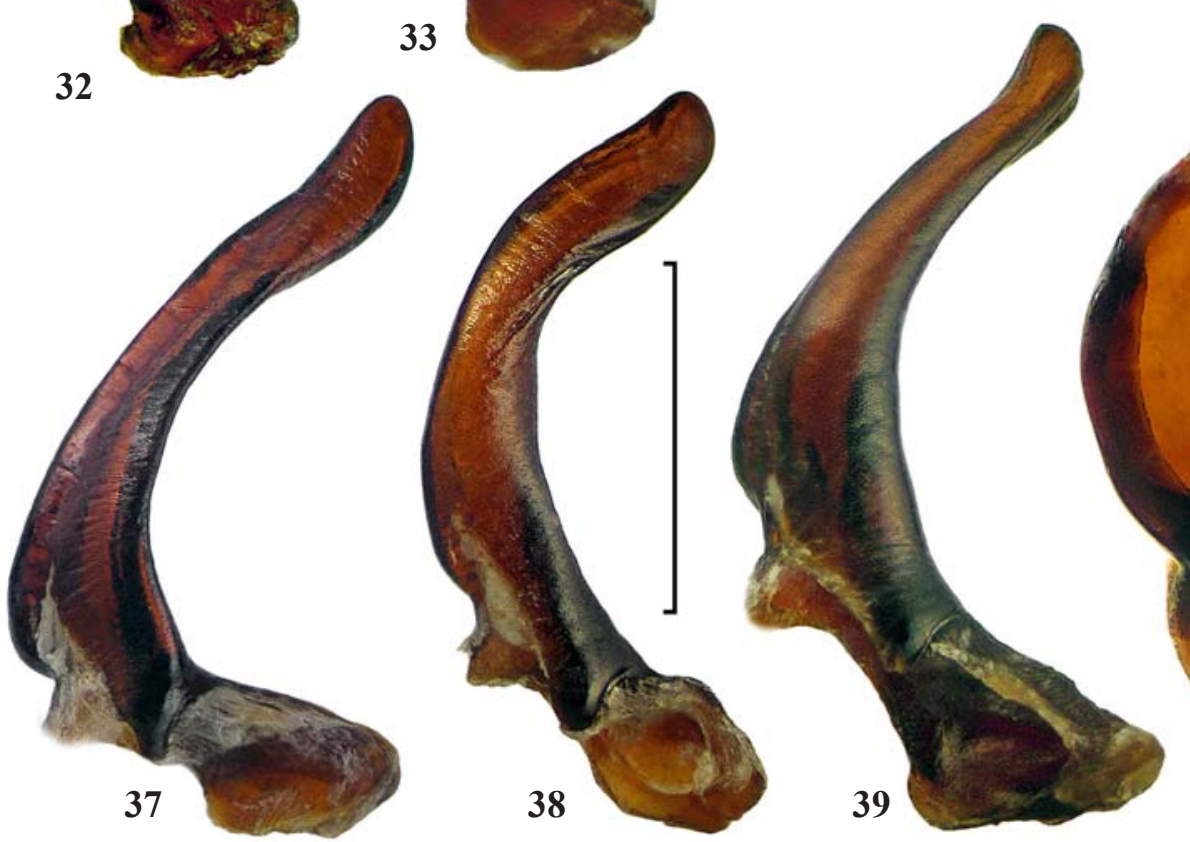

39

Figs 32-40. Parameres: 32 - Pterostichus obliteratus sp.n.; 33, $40-$ P. cavifrons sp.n.; $34-$ P. pseudoviolaceus sp.n.; 35-36 - P. violaceus; 37 - P. sulcatipennis sp.n.; 38 - P. glymmiger; 39 - P. asulcatus sp.n.; 32-35, 37-39 - left paramere, right aspect; 36, $40-$ right paramere, left aspect. Scale bar $1 \mathrm{~mm}$.

Рис. 32-40. Парамеры: 32 - Pterostichus obliteratus sp.n.; 33, 40 - P. cavifrons sp.n., 34 - P. pseudoviolaceus sp.n.; 35-36 P. violaceus; 37 - P. sulcatipennis sp.n.; 38 - P. glymmiger; $39-P$. asulcatus sp.n.; 32-35, 37-39 - левая парамера, вид справа; 36, 40 - правая парамера, вид слева. Масштаб 1 мм. 
and 2 nd confluent apicad in succession, separated from interval 1 and lateral edge, these two fused at sutural angle. Interval 8 slightly to considerably narrower than 7 th, about as wide as 9th. Reflexed lateral margin narrow and (almost) smooth. Parascutellar setigerous pore close to stria 1; parascutellar striole and discal setae missing. Stria 7 with a single preapical seta, anterior. USS consisting of 15-17 setae.

Underside smooth, except for mesepisternum rather sparsely punctate in median concavity; punctures large yet fairly shallow; sometimes basal half of mesepisternum or metepisternum with a few punctures. Prosternum in basal two thirds with a distinct to vague medial groove. Prosternal process in lateral view slightly obtuse, with apex rounded and barely projecting beyond procoxa; apical angles rounded in ventral view. Abdominal sternites conspicuously beaded on sides, except base of sternite II; sternite VII similar in the sexes.

Legs: $f e 1$ posteriorly bisetose (posterobasal seta missing); til slightly dilated apicad, with preapical spinule separated from two apical ones. Tarsi laterally neither carinate nor sulcate; $t m 5$ glabrous ventrally.

Aedeagus (Figs 13, 20, 34): median lobe most similar to that of $P$. sulcatipennis sp.n., nearly arculate owing to very short basal part; ventral side in lateral view straight medially, bent ventrad in apical third. Terminal lamella in dorsal view nearly the same, but much shorter. Right paramere moderately long and tapering, with rounded tip.

Gonocoxite (Fig. 46) with blunt apex and 2-3 ensiform setae (one female examined)

DIAGNOSIS. Similar to $P$. violaceus in having a fairly small violaceous body and the cordate pronotum. Apically broadened elytral striae and a similar aedeagus suggest closer relationships between $P$. pseudoviolaceus sp.n. and $P$. sulcatipennis sp.n.

DISTRIBUTION. Known from the type locality only.

NAME. Reflects the similarity of the species with $P$. violaceus in appearance.

HABITATS AND HABITS. All specimens were taken by pitfall traps in monsoon forests, some of them together with P. sulcatipennis sp.n.

\section{Pterostichus (Steropanus) sulcatipennis Fedorenko, sp.n.}

Figs 7, 11, 18, 37, 48 .

MATERIAL. Holotype $\sigma^{7}$ (ZMMU) and paratypes, $\sigma^{7}, 2$ 우 (SIEE), labelled 'Vietnam, Kon Tum Prov[ince], 2-3 km W of Ngoc Linh Mt., $15^{\circ} 05^{\prime} \mathrm{N}, 107^{\circ} 57^{\prime} \mathrm{E}, \mathrm{h}=1600-2150 \mathrm{~m}$, pitfall traps, $19 . \mathrm{III}-$ IV.2006, leg. A. Anichkin'; paratypes 2 우 (ZISP) labelled 'Centra Highlands, $2-3 \mathrm{~km} \mathrm{~W}$ of Ngoc Linh Mt. $15^{\circ} 05^{\prime} \mathrm{N}, 107^{\circ} 57^{\prime} \mathrm{E}, 1700$ 1900 m, 5.III-14.IV.2004, A.V. Abramov'.

DESCRIPTION. Body (Fig. 7), BL 15.8-18.2 mm. Shiny black, with less shiny head and pronotum. Antennae, protarsi, protibiae toward apices and femora apically reddishbrown; palps and antennomeres 5-11 along ridges red; apical palpomeres somewhat infuscate while yellow in apical 1/3-2/ 5. Microsculpture distinct on head and pronotum, isodiametric or moderately transverse, respectively; more superficial, isodiametric to moderately transverse on elytral intervals except along striae, very superficial, consisting of very oblique narrow meshes close to striae. Elytral striae with coarse isodiametric microsculpture so that elytra dull before apex, except for shiny costate-to-carinate elytral intervals.

Eyes fairly small and prominent; gena rather long, about two fifths as long as eye, meeting neck at highly obtuse angle or extended into neck in a smooth curve. Frontal sulci smooth, very deep, shallower posteriorly, moderately long S-shaped, i.e., parallel behind clypeus, then curved outwards, and afterwards curved posteriad, terminating on a level with anterior supraocular seta. Labrum with slightly sinuate apex; distance between outer two setae barely greater than between medial four setae. Antennae not quite reaching pronotal base in female, almost reaching or slightly surpassing base of elytra in male.

Penultimate labial palpomere trisetose at inner margin (posterior latero-apical seta missing), with apical seta at outer margin. Apical maxillary palpomere fusiform $(+)$ or subfusiform, with barely wider apex $\left(\sigma^{7}\right)$; apical labial palpomere subfusiform in the sexes, barely tapered in apical third, with apex slightly less than two fifths as long as inner margin $\left(O^{7}\right)$ or barely narrower $(+)$.

Pronotum convex, subquadrate, PW/PL 1.23-1.26 (mean $1.25, \mathrm{n}=5), \mathrm{PW} / \mathrm{HW} 1.58-1.70$ (1.64), broadest before middle, PLw/PL 0.36-0.49 (0.44); sides rounded, indistinctly sinuate just in front of basal angles. Base sinuate medially, oblique towards obtuse basal angles, slightly wider than apex, $\mathrm{PWb} / \mathrm{PWa} 1.10-1.17$ (1.15). Apex sinuate, barely convex inside apical angles, finely beaded in lateral third; apical angles slightly less than right, projecting a little, with blunt apices. Lateral bead entire, narrow, barely wider basally; lateral groove deep, wide, as wide as lateral bead in general, barely wider at middle, finely and rather densely punctate, as a fine impressed line extended along basal margin to inner basal sulcus. Inner basal sulcus moderately deep at bottom of a more or less shallow oblong fovea, terminating $2 / 5$ from base; punctures varying from very few medium-sized to coarse at base of the sulcus to coarse and dense in, along, and/or outside the sulcus. Outer basal sulcus missing. Disc smooth. Median line deep, almost reaching base and apex, indistinctly crenulate.

Elytra elliptic, EL/EW 1.63-1.64 (1.64), EW/PW 1.201.22 (1.21), broadest at about middle, with shallow preapical sinuation; internal preapical plica usually much reduced; sides often straight in basal $2 / 5$ or indistinctly sinuate a fifth from base. Base oblique, humeri somewhat rounded, with a conspicuous humeral tooth; basal ridge outside stria 3, oblique from humerus; humeral angle obtuse. Striae (including 9th) finely yet conspicuously punctate all along, very deep, increasingly broadened apicad, becoming widely sulcate before apex, with carinate intervals in between. Intervals costate, 8th and 9th very narrow, (sub)carinate; 7 th, 5th, 3rd and 2nd confluent apicad in succession; interval 1 fused to lateral edge in sutural angle, separated from interval 2. Reflexed lateral margin broadened in apical 2/3-3/4, preapical sinuation excluded. Parascutellar setigerous pore close to stria 1; parascutellar striole and discal setae missing. Stria 7 with a single, anterior, preapical seta. USS consisting of 18-19 setae.

Underside. Prosternum with a vague medial groove in basal two thirds or in middle third only. Prosternal process in lateral view slightly more than rectangular and blunt, with apical angles fairly sharp in ventral view. Abdominal lateral bead conspicuous, shallower on, and absent from base of, sternite II; sternite VII similar in the sexes. Mesepisternum sparsely to moderately punctate on oblique median concavity, without or with a few finer punctures in front; metepisternum smooth or with several punctures.

Legs: $f e 1$ posteriorly bisetose (posterobasal seta missing); $t i 1$ barely dilated apicad, with preapical spine separated from two apical spines. Tarsi laterally neither carinate nor sulcate; ta 5 glabrous ventrally.

Aedeagus (Figs 11, 18, 37): median lobe geniculate, with a short basal part; ventral side in lateral view straight medially and bent ventrad in apical third. Terminal lamella in dorsal view wide, long, parallel-sided, slightly curved to the left behind the middle, widely rounded apically. Right paramere long, subclavate, with slightly upturned apex. 
Gonocoxite (Fig. 48) robust, with blunt apex and two ensiform setae.

DISTRIBUTION. The type locality only.

NAME. Refers to the elytral striae being widely sulcate before apex.

HABITATS AND HABITS. At least four of totally six specimens were taken by pitfall traps in monsoon forests.

\section{Pterostichus (Steropanus) cavifrons}

Fedorenko, sp.n.

Figs 8, 12, 19, 28-29, 33, 40, 45.

MATERIAL. Holotype $\sigma^{7}$ (ZMMU) and paratypes, $\sigma^{7} \sigma^{7}$, + (SIEE, ZISP), labelled 'Vietnam, Gia Lai Province, $\sim 50 \mathrm{~km} \mathrm{~N}$ of An Khe, Kon Chu Rang Nat[ure]. Reserv[e]., 143- 31 N N $/ 108^{\circ} 32^{\prime} \mathrm{E}, \mathrm{h}=1000$ $1040 \mathrm{~m}$, pitfall traps, 24.V-2.VI.2016, leg. D. Fedorenko'. Paratypes: (SIEE) 'Vietnam, Kon Tum Prov[ince]., Kon Plong Distr[ict]., $14^{\circ} 45^{\prime} \mathrm{N} 108^{\circ} 17^{\prime} 51^{\prime \prime} \mathrm{E}$, env. ngok Boc I Mt., $\mathrm{h}=1300-1400 \mathrm{~m}, 8^{-}$ 10.VI.2016, D. Fedorenko leg.'; 2 웅, 'Vietnam, Gia Lai Province, $\sim 40 \mathrm{~km}$ ENE of Pleiku, $14^{\circ} 12^{\prime} 11^{\prime \prime} \mathrm{N} / 108^{\circ} 18^{\prime} 54^{\prime \prime} \mathrm{E}$, Kon Ka Kinh Nat[io]n[al]. Park, h=900-950 m, 24-30.V.2017, D. Fedorenko leg.' $\mathrm{O}^{7}$ (ZISP) labelled 'Vietnam, Gialai-Kontum [Province], Buonloi, 15 XI 1993, Gorokhov' [in Russian], 'Tritrichis aegua Andr.' [hw], 'From collection of O.N. Kabakov' [in Russian].

DESCRIPTION. As for the previous species, except as follows. Body smaller (Fig. 8), BL 12.6-14.7 mm, shiny black. Microsculpture similar yet rather superficial throughout, elytra shiny due to narrow elytral striae.

Eyes small and protruding laterad beyond gena. Frontal sulci smooth and long, being parallel, short, wide and ex- tremely deep behind clypeus, then diverging, very deep up to the level of anterior supra-ocular seta; increasingly shallower behind, disappearing slightly beyond the level of posterior supra-ocular seta and forming a blunt carina above the setae. Vertex inside the sulci mostly with a pair of short, more or less impressed, longitudinal to slightly oblique striae. Labrum truncate or slightly sinuate; distance between outer two setae barely greater than between median four setae. Antennae reaching basal third $(+)$ or fifth $\left(O^{7}\right)$ of pronotum.

Penultimate labial palpomere quadrisetose at inner margin, with apical seta at outer margin. Apical maxillary palpomere subfusiform $(+)$ or subtriangular $\left(O^{7}\right)$, with apex about a third as long as inner margin; apical labial palpomere triangular, with apex slightly more than half (†) or slightly less than two thirds $\left(\mathrm{O}^{7}\right)$ as long as inner margin.

Pronotum subcordate and larger, PW/PL 1.22-1.29 (mean 1.26, $\mathrm{n}=5), \mathrm{PW} / \mathrm{HW} 1.67-1.76$ (1.71), PLw/PL 0.44-0.47 (0.45), PWb/PWa 1.11-1.16 (1.14); sides very slightly sinuate in front of basal angles. Apex sinuate in general, being nearly straight medially and distinctly convex inside apical angles, which only project at tips. Apical bead totally obliterate. Lateral bead narrow; lateral groove densely punctate, narrow close to apical angles, otherwise very wide, twice as wide as lateral bead at middle. Inner basal sulci rather shallow and smooth, traceable in basal two fifths, not quite reaching base, basally deeper and slightly converging apicad, and then running parallel to each other. Median line very deep, sulciform.
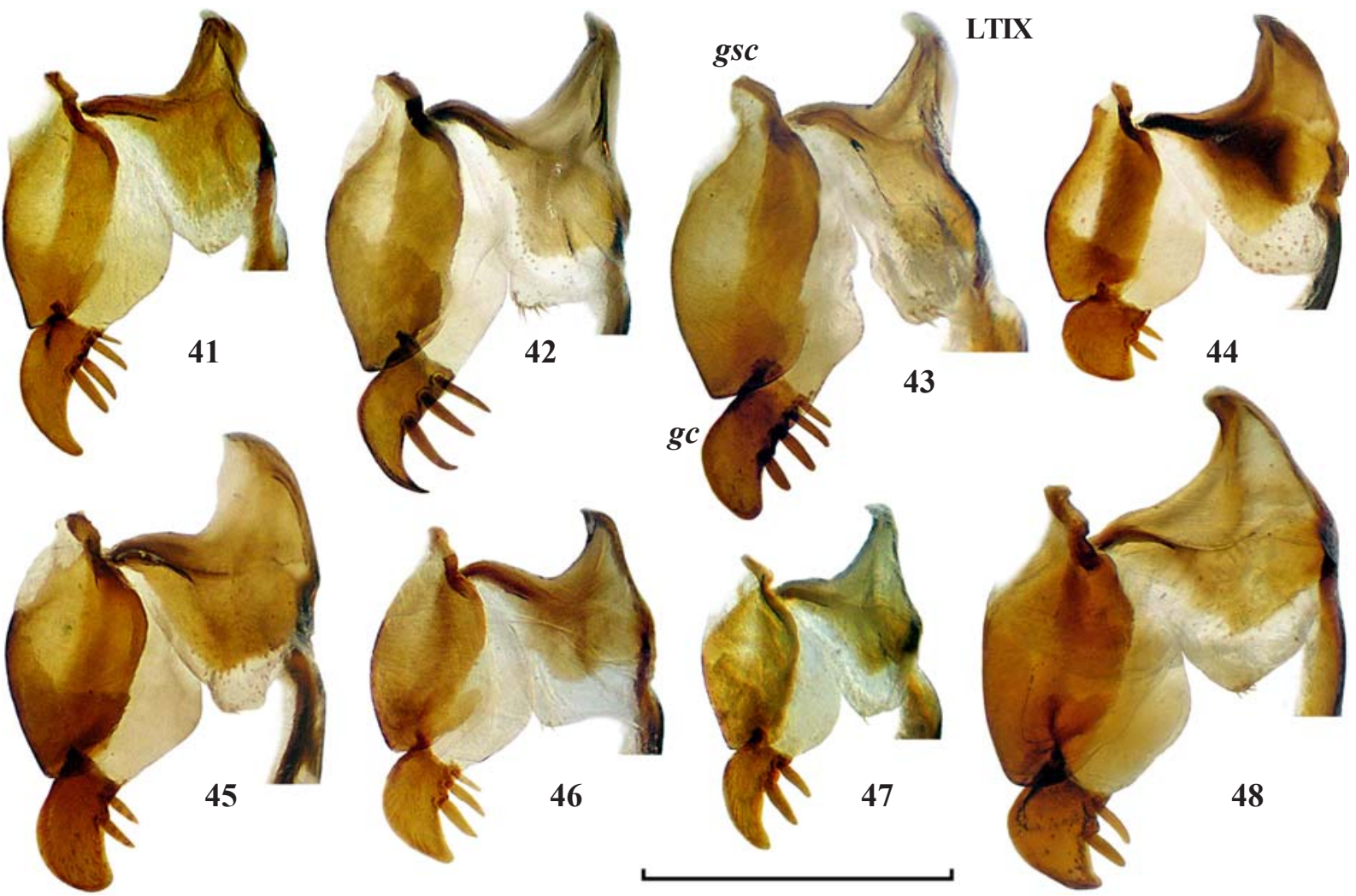

43
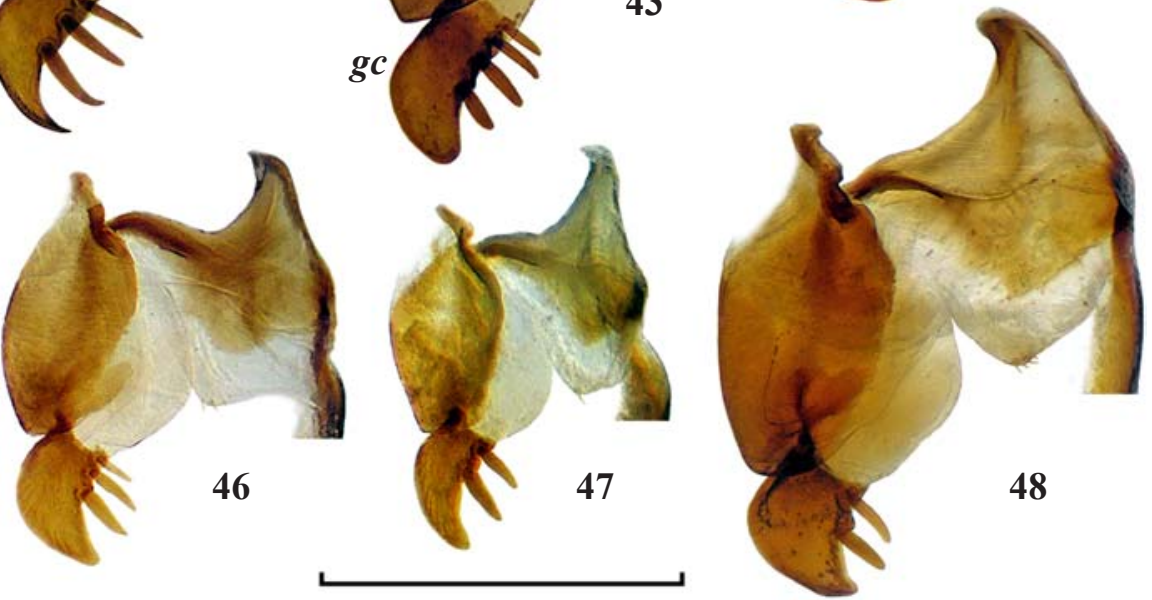

Figs 41-48. Left female stylus, ventral aspect: 41 - Pterostichus obliteratus sp.n.; 42 — P. kataevi sp.n.; 43 - P. asulcatus sp.n.; 44 Pterostichus (Pseudethira) gagates; $45-$ - P. cavifrons sp.n.; $46-$ P. pseudoviolaceus sp.n.; $47-P$. violaceus; $48-$ P. sulcatipennis sp.n.; gc - gonocoxite, gsc - gonosubcoxite, LTIX — laterotergite IX. Scale bar $1 \mathrm{~mm}$.

Рис. 41-48. Левый стилюс самки, вентрально: 41 - Pterostichus obliteratus sp.n.; 42 - P. kataevi sp.n.; 43 - P. asulcatus sp.n.; 44 - Pterostichus (Pseudethira) gagates; 45 - P. cavifrons sp.n.; 46 - P. pseudoviolaceus sp.n.; 47 - P. violaceus; 48 - P. sulcatipennis sp.n.; $g c$ - гонококсит; gsc - гоносубкоксит, LTIX - латеротергит IX. Масштаб 1 мм. 
Elytra shorter, rounded on sides, EL/EW 1.55-1.62(1.58), EW/PW 1.10-1.16 (1.12); base transverse, convex forward, humeri angulate due to conspicuous humeral teeth, preapical sinuation missing, internal preapical plica almost totally reduced. Basal ridge outside stria 5. Striae very deep all along, deeper apically, conspicuously punctate, finely in basal half, moderately before apex. Punctures in striae becoming foveate close to apex, with 2-3 posteriormost punctures modified into a deep cavities. Intervals costate, 8 th about as wide as 7 th and 9th, barely constricted before the site of preapical sinuation. Intervals 7, 5, 3 and 2 confluent apicad in succession, then merged in interval 1 and lateral edge in sutural angle, thus forming a small apical tubercle projecting slightly apicad beyond elytral apex. USS consisting of 19-20 setae.

Underside. Prosternal process in lateral view projecting beyond procoxa, rectangular to slightly acute, sharp or barely blunted; apical angles sharp in ventral view. Abdominal lateral bead entire and conspicuous. Sternite VII with apical two fifths very gently flattened and limited anteriorly by a vague transverse ridge in male. Mesepisternum rather coarsely and more or less densely punctate at middle, often with a few punctures before and behind; metepisternum coarsely punctate to smooth.

Aedeagus (Figs 12, 19, 33, 40): median lobe arcuate owing to a very short basal part, ventral side in lateral view evenly concave, except apical lamella bent slightly ventrad. Apical lamella in dorsal view short and widely rounded apically. Right paramere moderately long, subclavate. Everted and inflated inner sac (Figs 28-29) with a medium-sized and fairly weak apical sclerite and two apical bulbs, small right and larger left.

Gonocoxite (Fig. 45) rather widely rounded apically (even in younger female specimens), with two ensiform setae.

DIAGNOSIS. Very distinctive among the other consubgeners in having non-metallic body, very deep frontal sulci, very widely sulcate and densely punctate lateral grooves of the pronotum, punctate elytral striae, with punctures deeply foveate before apex.

DISTRIBUTION. Hitherto known from three close localities in the highlands of Kon Tum and Gia Lai provinces.

NAME. Refers to extremely deep frontal sulci.

HABITATS AND HABITS. This species inhabit primary broad-leaved or mixed monsoon forests at 1000-1400 m altitudes. In the type locality, all specimens were taken by hands along trails in night-time, except for the female collected by a pitfall trap on the Mt. Ngok Boc.

\section{Pterostichus (Steropanus) violaceus (Straneo, 1949)}

Figs 5, 16, 23, 30-31, 35-36, 47.

Straneo, 1949: 8 (Tritrichis; Annam, Dalat).

MATERIAL. Holotype, photographed female specimen (MSNM) with labels: 'DALAT ANNAM, III.-IV.1924', red 'Holotypus violacea Stran.' [hw], 'Tritrichis ? violacea n.sp. [hw], det. S L. Straneo 1948'.

Additional material. $140^{\top} \sigma^{\top}, 2190$ (SIEE), Southern Vietnam, Lam Dong Province, Bi Doup - Nui Ba Nature Reserve, $12^{\circ} 07 \mathrm{~N}$ $108^{\circ} 39^{\prime 2} 0^{\prime \prime} \mathrm{E}$, Bi Doup Mt., northern slope, $\mathrm{h}=1700-1900 \mathrm{~m}, 3-$ 22.IV.2008 and 9-16.V.2009, leg. D. Fedorenko; 우 (SIEE) same data, except for $12^{\circ} 10^{\prime} 44^{\prime \prime} \mathrm{N} 108^{\circ} 40^{\prime} 44^{\prime \prime} \mathrm{E}$, env. Long Lanh, $\mathrm{h}=1400$ 1600 m, 3-6.IV.2008; 3 우 (SIEE), Dak Lak Province, Chu Yang Sin National Park, $12^{\circ} 22^{\prime} 40^{\prime \prime} \mathrm{N} 108^{\circ} 21^{\prime} 11^{\prime \prime} \mathrm{E}, 1.5 \mathrm{~km}$ W of Chu Pan Phan Mt, h=1650 m, 30.III-11.IV.2012 and 19.III-2.IV.2013.

REDESCRIPTION. Body small (Fig. 5), BL 9.8-11.1 $\mathrm{mm}$, metallic violaceous. Underside and legs violaceous black. Body appendages otherwise coloured as in other consubgeners. Labrum reddish or red in basal half. Microsculpture super- ficial, isodiametric on head, slightly transverse on pronotum, more or less transverse on elytra (see also 'Comments').

Eyes small and protruding; gena long, three fifths as long as eye, meeting neck at very obtuse angle. Frontal sulci as in $P$. cavifrons sp.n., but much shallower anteriorly, very deep behind clypeus and increasingly shallower behind. Labrum sinuate apically, distance between outer two setae barely greater than between medial four ones. Antennae reaching basal third $(+)$ or fifth $\left(\sigma^{7}\right)$.

Mandibles excavated dorsally in basal two fifths, leaving dorsal scrobal ridge carinate, slightly sinuate laterally, ending in an oblong boss, which is much more distinct than in the other consubgeners. Penultimate labial palpomere trisetose at inner margin (posterior latero-apical seta missing), with apical seta at outer margin. Apical maxillary palpomere subcylindrical $\left(\sigma^{7}\right)$ or fusiform $(+)$ in apical half. Apical labial palpomere triangular (pentagonal), parallel-sided in apical half $\left(O^{7}\right)$ or slightly tapering in apical two thirds $(+)$, with apex nearly half $\left(\sigma^{7}\right)$ or slightly more than two fifths $(+)$ as long as inner margin.

Pronotum cordate, PW/PL 1.16-1.20 (mean 1.18, $\mathrm{n}=7$ ), PW/HW 1.57-1.65 (1.60), broadest just before middle, PLw/ PL $0.44-0.50(0.48)$, sides rounded, very gently to distinctly sinuate in front of fairly sharp, slightly obtuse to nearly right basal angles. Base barely wider than apex, PWb/PWa 1.021.07 (1.05), sinuate medially, oblique laterally. Apex evenly sinuate, very finely beaded in lateral fourth; apical angles slightly acute. Lateral bead entire and narrow; lateral groove narrow, nearly smooth to minutely and rather densely punctate at bottom. Inner basal sulcus as a very shallow oblong impression in basal 1/3-1/4; outer basal sulcus and basal bead both missing, except for a vague trace of angulate stria close to posterolateral seta. Disc smooth. Median line deep, indistinctly crenulate, almost reaching base and apex.

Elytra elliptic, EL/EW 1.50-1.59 (1.56), EW/PW 1.151.21 (1.19), broadest at about middle, with base oblique, except for a minute indentation close to peduncle; humeri rounded, without or with a vestigial tooth traceable in ventrolateral view; preapical sinuation very shallow, with internal plica much reduced yet visible in lateral view. Basal ridge outside stria 3 in addition to two deep pores at bases of striae 1 and 2; humeral angle indistinct or highly obtuse. Striae deep, minutely to finely punctate; 9 th more distinctly, finely to moderately, punctate. Intervals convex, 9 th narrow throughout, 8th slightly to distinctly narrower than $7 \mathrm{th} ; 7 \mathrm{th}, 5$ th and 3 rd confluent apicad in succession, apically separated from interval 2 and interval 1 fused to lateral edge at sutural angle. Reflexed lateral margin not or barely broadening apicad. Parascutellar setigerous pore close to stria 1; parascutellar striole and discal setae missing. Stria 7 with two, exceptionally one, preapical setae. USS consisting of 17 (rarely 16) setae, setae 1-7 widely separated from setae 9-17.

Underside: Prosternum in basal $2 / 3$ with a deep medial groove. Prosternal process in lateral view slightly acute, rounded apically, apical angles rounded in ventral view. Abdominal lateral bead conspicuous, usually obsolete on sternite II to base of III; VII similar in the sexes. Median concavity of mesepisternum sparsely to vaguely punctate.

Legs: $f e 1$ posteriorly bisetose (posterobasal seta missing); til dilated apicad, extending into a short apical lobe at posterolateral ridge, with one preapical spinule and two close apical ones (sometimes with 1-2 or four unilateral spinules). Tarsi laterally neither carinate nor sulcate; $t m 5$ glabrous ventrally.

Aedeagus (Figs 16, 23, 35-36): median lobe geniculate, with very long basal part; ventral margin in lateral view then straight, with a preapical convexity and apex bent ventrad; 
ventral side basal to the convexity with an oblong concavity for reception of apex of very short right paramere. Apical lamella in dorsal view very wide, shorter than wide and widely rounded. Left paramere with narrow subbasal process almost totally reduced (Fig. 36). Everted and inflated internal sac (Figs 30-31) directed apicad, with a small digitiform basal sclerite. setae.

Gonocoxite (Fig. 47) with blunt apex and two ensiform

DISTRIBUTION. Endemic to the Dalat Plateau within Lam Dong and Dak Lak provinces, Vietnam.

HABITATS AND HABITS. The species inhabits broadleaved monsoon forests at 1450-1900 m elevations. Most specimens were collected by pitfall traps, the others by hands under logs.

COMMENTS. Very distinctive within the subgenus in having the mentum asetose ( $v s$. bisetose), right paramere short, the internal sac curved apicad ( $v s$. ventrad), and the left paramere unusual within Steropanus and Pterostichus; all these characters are derived. Otherwise the species matches well the diagnostic combination of either Steropanus or its some species groups, or species. It shares similar frontal sulci and conspicuously punctate elytral stria 9 with $P$. sulcatipen$n i s$ sp.n. and $P$. cavifrons sp.n. These facts combined suggest close relationships between the three species, with $P$. violaceus among them being advanced farthest.

In this species, dorsal microsculpture varies to a degree between populations. It is distinct on the head and pronotum and moderately transverse on the elytra in the specimens from the Bi Doup - Nui Ba Nature Reserve. The specimens from the Chu Yang Sin National Park have a distinctly fainter microsculpture and, accordingly, the body shinier and somewhat opalescent: the microsculpture is almost vanished from the forebody and barely traceable on the elytra, consisting of strongly transverse meshes to fine transverse lines.

\section{Pterostichus (Steropanus) alveolatus Fedorenko, sp.n. \\ Fig. 9.}

MATERIAL. Holotype (ZMMU) 'Vietnam, Kon Tum Prov[ince]., Kon Plong Distr[ict]., 14 ${ }^{\circ} 45^{\prime} 13^{\prime \prime} \mathrm{N} / 108^{\circ} 17^{\prime} 40^{\prime \prime} \mathrm{E}$, env. ngok Boc I Mt., $\mathrm{h}=1300-1500 \mathrm{~m}, 8-23 . I V .2015$, D.Fedorenko leg.'.

DESCRIPTION. Isolated elytra only (Fig. 9). BL ca. 13.5 $\mathrm{mm}$. Elytra shiny black, apically broadened striae dull. Microsculpture superficial, consisting of very transverse meshes; striae with coarse microsculpture of slightly longitudinal meshes that become isodiametric before apex.

Elytra elliptic, rounded on sides, EL/EW 1.62. Base narrow, slightly oblique and convex forward; humeri angulate, with a small tooth, preapical sinuation indistinct; internal plica ventral, small yet traceable in lateral view. Basal ridge outside stria 3 in addition to two small foveae retained just in front of bases of striae 1 and 2. Striae deep, increasingly broadened apicad in apical third, rather finely yet conspicuously punctate at bottom, shallowly alveolate before apex; striae 1-3 indistinctly punctate in basal half. Intervals 1-4 slightly convex in basal two thirds, 5-8th convex there, 6th costate behind humerus; all intervals becoming costate apicad and carinate close to apex; 8th barely narrower than 7th; 9th subcarinate all along. Intervals 7, 5, 3 and 2 confluent apicad in succession, being separated from interval 1 which is fused to lateral edge in sutural angle. USS consisting of 19 setae.

DIAGNOSIS. The elytra are distinctive owing to the striae punctate and widely though shallowly grooved before apex, and interval 3 with discal seta. In the elytral striation, $P$. alveolatus sp.n. is most similar to $P$. cavifrons sp.n. and, especially, P. sulcatipennis sp.n. The latter is larger, with no discal elytral setae; the elytral intervals more coarsely microsculptured, with meshes being distinctly less transverse.

NAME. Refers to shallowly alveolate elytral striae.

DISTRIBUTION. Only known from the type locality.

HABITATS AND HABITS. The connate elytra of this species were found under a tree trunk at $1500 \mathrm{~m}$ elevation.

ACKNOWLEDGEMENTS . I am very indebted to Dr. B.M. Kataev (ZISP) for the loan of the material under his care and Dr. Fabrizio Rigato (MSNM) for high-resolution photographs of the holotype of $P$. violaceus. I thank Dr. Alexander Anichkin (Yoshkar-Ola) for donating specimens.

\section{References}

Andrewes H.E. 1937. Papers on Oriental Carabidae. - XXXI // Ann. Mag. Nat. Hist. Ser.9. Vol.19. P.489-495.

Bousquet Y. 2003. Tribe Pterostichini Bonelli, 1810 // I. Löbl, A. Smetana (eds.). Catalogue of Palaearctic Coleoptera. Vol.1. Archostemata - Adephaga - Myxophaga. Stenstrup: Apollo Books Publ. 819 p.

Bousquet Y. 2017. Tribe Pterostichini Bonelli, 1810 // I. Löbl, D. Löbl (eds.). Catalogue of Palaearctic Coleoptera. Vol.1. Archostemata - Adephaga - Myxophaga. Revised and updated edition. Vol.1. Leiden-Boston: Brill Publ. 1443 pp.

Fairmaire L. 1889 [1888]. Coléoptères de l'intérieur de la Chine // Ann. Soc. Ent. Belg. T.32. P.7-46.

Jedlička A. 1931. Neue Carabiden aus Süd-China und Persien // Časopis Čsl. Spol. Entom. Vol.28. S.133-137.

Jedlička A. 1962. Monographie des Tribus Pterostichini aus Ostasien (Pterostichi, Trigonotomi, Myadi) (Coleoptera, Carabidae) // Entom. Abh. Ber. Mus. Tierk. Dresden. Bd.26. No.21. S.177346.

Lorenz W. 1998. Systematic list of extant ground beetles of the World (Insecta Coleoptera "Geadephaga": Trachypachidae incl. Paussinae, Cicindelinae, Rhysodinae). 1st Edition. Tutzing. 502 pp.

Lorenz W. 2005. Systematic list of extant ground beetles of the World (Insecta Coleoptera "Geadephaga": Trachypachidae incl. Paussinae, Cicindelinae, Rhysodinae). 2nd Edition. Tutzing. $530 \mathrm{pp}$.

Morvan D.m. 1992. Contribution à la connaissance des Coléoptères Carabidae de Thaïland // Elytron. 1991. Vol.5. P.55-62

Schmidt J. 2006. Die Pterostichus-Arten des subgenus Pseudethira Sciaky, 1996, in Zentral- und West Nepal (Coleoptera, Carabidae): Taxonomie, Phylogenie, Biogeographie // Hartmann M., Weipert J. (eds.). Biodiversität und Naturausstattung im Himalaya. Vol.2. Verein der Freunde und Förderer des Naturkundsmuseums Erfurt. Erfurt. S.179-243.

Schmidt J. 2012. New Pterostichus species from the Eastern Himalaya, with a revision of the atrox group of the subgenus Pseudethira Sciaky, 1996 (Insecta: Coleoptera: Carabidae: Pterostichini) Hartmann M., Weipert J. (eds.). Biodiversität und Naturausstattung im Himalaya. Vol.4. Verein der Freunde und Förderer des Naturkundsmuseums Erfurt. Erfurt. S.225-257.

Sciaky R. 1996. New taxa and new synonyms among Pterostichinae from Asia // Entomofauna. Bd.17. H.29. S.429-440.

Sciaky R., Allegro G. 2013. Two new subgenera and two new species of Pterostichus from China (Coleoptera, Carabidae) // Boll. Mus. Stor. Nat. Verona. Vol.37. Bot. \& Zool. P.113-122.

Straneo S.L. 1949. Nuovi Pterostichini (Coleoptera Carabidae) (V nota) // Bull. Inst. Sci. Nat. Belg. T.25. No.21. P.1-9.

Straneo S.L. 1989. Nuovi Pterostichini asiatici (Coleoptera, Carabidae) // Boll. Mus. reg. Sci. Nat. Torino. Vol.7. No.2. P.273286.

Tschitschérine T. 1897 [1896]. Matériaux pour servir à l'étude des Feroniens // Horae Soc. Ent. Ross. T.30. P.260-351. 